\title{
Site-Specific Labelling of Endogenous Proteins Using CoLDR Chemistry
}

Rambabu N. Reddi ${ }^{1,}{ }^{*}$, Adi Rogel ${ }^{1,{ }^{*}}$, Efrat Resnick ${ }^{1}$, Ronen Gabizon ${ }^{1}$, Pragati Kishore Prasad ${ }^{1}$, Neta Gurwicz $^{2}$, Haim Barr ${ }^{3}$, Ziv Shulman², Nir London ${ }^{1, H}$

${ }^{1}$ Dept. of Chemical and Structural Biology, The Weizmann Institute of Science, Rehovot, 7610001, Israel.

${ }^{2}$ Dept. of Immunology, The Weizmann Institute of Science, Rehovot, 7610001, Israel.

${ }^{3}$ Wohl Institute for Drug Discovery of the Nancy and Stephen Grand Israel National Center for Personalized Medicine, The Weizmann Institute of Science, Rehovot, 7610001, Israel

$*$ Equal contribution

\# To whom correspondence should be addressed, nir.london@weizmann.ac.il

Keywords: Bioconjugation, covalent inhibitors, CoLDR, protein half-life, PROTAC, Targeted protein degradation, Turn-on fluorescence, Ligand directed chemistry 


\section{Supporting Chemistry}

1. Materials and methods: All reagents and solvents were obtained from commercial suppliers unless otherwise mentioned. Ibr-H (CAS 1022150-12-4) was purchased from BLD pharmatech. (5S)-4-(6-fluoro-7-(2-fluoro-6-hydroxyphenyl)-1-(2-isopropyl-4-methylpyridin3-yl)-2-oxo-1,2-dihydropyrido[2,3-d]pyrimidin-4-yl)-5-methyl-2,3,4,5-tetrahydropyrazin-1ium (AMG-510 amine) was purchased from Enamine. Compound 1q was previously synthesized in our lab and used as such. ${ }^{1}$ Deuterated solvents were purchased from Cambridge isotope laboratories and all other reagents are purchased from Sigma Aldrich and used as such without further purification.

Aluminum-backed silica plates (Merck silica gel 60 F254) were used for thin layer chromatography (TLC) to monitor solution phase reactions. The purification of compounds was carried out on a combi flash chromatography and waters RP-HPLC with Prep C18 column. The ${ }^{1} \mathrm{H}-\mathrm{NMR}$ and ${ }^{13} \mathrm{CNMR}$ spectra were recorded using a $400 \mathrm{MHz}$ and $500 \mathrm{MHz}$ Bruker advance spectrometers and were calibrated using residual undeuterated solvent as the internal references $\left(\mathrm{CDCl}_{3}: 7.26 \mathrm{ppm}\right.$; DMSO-d6: $2.50 \mathrm{ppm} ; \mathrm{D}_{2} \mathrm{O}: 4.79 \mathrm{ppm}$ and $\left.\mathrm{CD}_{3} \mathrm{OD}=3.31 \mathrm{ppm}\right)$. Chemical shifts are reported in ppm on a $\delta$ scale. The following abbreviations were used to explain NMR peak multiplicities: $\mathrm{s}=$ singlet, $\mathrm{d}=$ doublet, $\mathrm{t}=$ triplet, $\mathrm{q}=$ quartet, $\mathrm{p}=$ pentet, $\mathrm{m}$ $=$ multiplet, $\mathrm{br}=$ broad. Most of the Ibrutinib derivatives appeared as a mixture of rotamers. The high-resolution mass spectra were recorded on Waters Xevo G2-XS QTof mass spectrometer using electrospray ionization time-of-flight (ESI-TOF) reflectron experiments.

2. Abbreviations. Acetonitrile (ACN), dichloromethane (DCM), N,N'-diisopropylethylamine (DIPEA), N,N'-dimethylformamide (DMF), Ethyl acetate (EtOAc), dimethyl sulfoxide (DMSO), 1-Ethyl-3-(3-dimethylaminopropyl) carbodiimide (EDC), 1[bis(dimethylamino)methylene]-1H-1,2,3- triazolo[4,5-b]pyridinium3-oxid hexafluorophosphate (HATU), methanol (MeOH), Phosphate buffer saline (PBS), highperformance liquid chromatography (HPLC), trifluoroacetic acid (TFA), 1,4diazabicyclo[2.2.2] octane (DABCO), diisopropylethyl amine (DIPEA) 
(R)-2-((3-(4-amino-3-(4-phenoxyphenyl)-1H-pyrazolo[3,4-d]pyrimidin-1-yl)piperidin-1yl)methyl)acrylic acid (Ibr-acid)<smiles>Nc1ncnc2c1c(-c1ccc(Oc3ccccc3)cc1)nn2[C@H]1CCCNC1</smiles>

Ibr-H<smiles>C=C(CBr)C(=O)O</smiles>

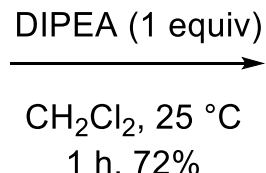
$1 \mathrm{~h}, 72 \%$

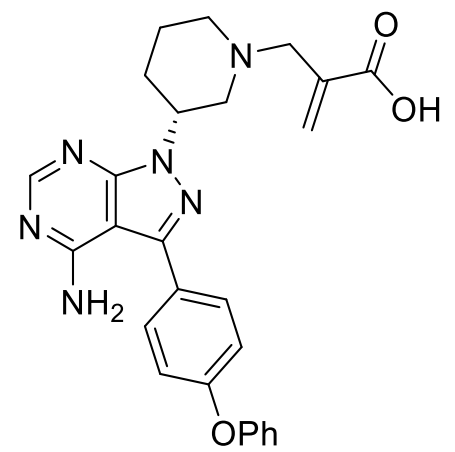

Ibr-acid

To a stirred solution of Ibr-H (387 mg, $1 \mathrm{mmol})$ in anhydrous DCM (6 mL), DIPEA (178 $\mu \mathrm{L}, 1$ mmol) and 2-(bromomethyl)acrylic acid (162 mg, $1 \mathrm{mmol})$ were added at $25^{\circ} \mathrm{C}$. The reaction mixture was stirred at room temperature for $1 \mathrm{~h}$. After completion of the reaction (as monitored by LC-MS), $\mathrm{CH}_{2} \mathrm{Cl}_{2}$ was concentrated in vacuo and the crude carboxylic acid was purified using combi flash column chromatography using MeOH:EtOAc (2:8) as eluent to give Ibr-acid in 335 $\operatorname{mg}($ yield $=72 \%)$

${ }^{1}$ H NMR (500 MHz, CD ${ }_{3} \mathrm{OD}$ ): $\delta 1.99$ (br. s., 2H), 2.19 (br. s., 1H), 2.24 (br. s., 1H), 3.74 (d, $J=16.2$ Hz, 2H), 4.10-4.20 (d, $J=13.2$ Hz, 3H), 5.33 (br. s., 1H), 6.29 (s, 1H), 6.68 (s, 1H), 7.10 (d, $J=7.7$ $\mathrm{Hz}, 2 \mathrm{H}), 7.13-7.23(\mathrm{~m}, 4 \mathrm{H}), 7.42(\mathrm{t}, J=8.0 \mathrm{~Hz}, 2 \mathrm{H}), 7.74(\mathrm{~d}, J=8.4 \mathrm{~Hz}, 2 \mathrm{H}), 8.34(\mathrm{~s}, 1 \mathrm{H}) ;{ }^{13} \mathbf{C}$ NMR (126 MHz, $\left.\mathrm{CD}_{3} \mathrm{OD}\right): \delta$ ppm 21.6, 28.8, 52.0, 53.7, 55.3, 59.7, 99.2, 120.1, 120.8, 125.4, 127.9, 131.3, $131.5,131.5,136.5,147.4,154.7,155.6,157.9,160.5,168.7$; ESI-MS (m/z): calculated for $\mathrm{C}_{26} \mathrm{H}_{27} \mathrm{~N}_{6} \mathrm{O}_{3}[\mathrm{M}+\mathrm{H}]+:$ 471.21; found: $[\mathrm{M}+\mathrm{H}]+: 471.45$.

Ethyl (R)-2-((3-(4-amino-3-(4-phenoxyphenyl)-1H-pyrazolo[3,4-d]pyrimidin-1-yl)piperidin-1yl)methyl)acrylate (1a)

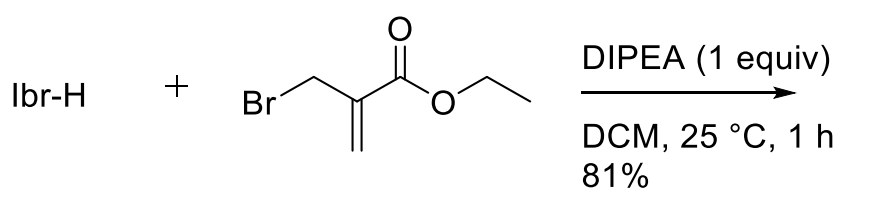<smiles>C=C(CBr)C(=O)OCC</smiles>

$1 \mathbf{a}$

To a stirred solution of Ibr-H $(38.7 \mathrm{mg}, 0.1 \mathrm{mmol})$ in anhydrous DCM (1 mL), DIPEA (17.3 $\mu \mathrm{L}, 0.1$ 
mmol) and ethyl bromo methacrylate $(14.6 \mu \mathrm{L}, 0.1 \mathrm{mmol})$ were added at $25^{\circ} \mathrm{C}$. The reaction mixture was stirred at room temperature for $1 \mathrm{~h}$. After completion of the reaction (as monitored by LC-MS), the reaction mixture was evaporated under vacuo and the crude product was purified by preparative HPLC using water:ACN (0.1\% TFA) solvent gradient to afford 1a as colorless solid in $40 \mathrm{mg}$ (yield $=81 \%)$.

${ }^{1}$ H NMR (500 MHz, CD $\left.30 D\right): \delta 1.28$ (t, $J=6.7$ Hz, 3H), 1.98-2.19 (m, 2H), 2.27 (br. s., 2H), 3.81 (d, $J=10.2 \mathrm{~Hz}, 1 \mathrm{H}), 4.08-4.18$ (m, 2H), 4.18-4.35 (m, 3H), 5.44 (br. s., 1H), 6.33 (s, 1H), 6.68 (s, 1H), 7.11 (d, $J=8.0 \mathrm{~Hz}, 2 \mathrm{H}), 7.14-7.23$ (m, 3H), 7.37-7.46 (m, 2H), 7.76 (br. s., 2H), 8.44 (s, 1H); ${ }^{13}$ C NMR (126 MHz, $\left.\mathrm{CD}_{3} \mathrm{OD}\right): \delta 14.5,28.6,36.9,52.4,53.8,55.5,59.4,63.3,98.7,120.1,120.9$, 125.5, 126.9, 131.3, 131.7, 136.8, 148.7, 153.8, 157.8, 160.9, 167.0; HR-MS (m/z): Calculated for $\mathrm{C}_{28} \mathrm{H}_{31} \mathrm{~N}_{6} \mathrm{O}_{3}[\mathrm{M}+\mathrm{H}]^{+}:$499.2458; Found $[\mathrm{M}+\mathrm{H}]^{+}: 499.2454$.

\section{(R)-N-(2-(2-((3-(4-amino-3-(4-phenoxyphenyl)-1H-pyrazolo[3,4-d]pyrimidin-1-yl)piperidin-}

\section{1-yl)methyl)acrylamido)ethyl)-4-formylbenzamide (1b)}

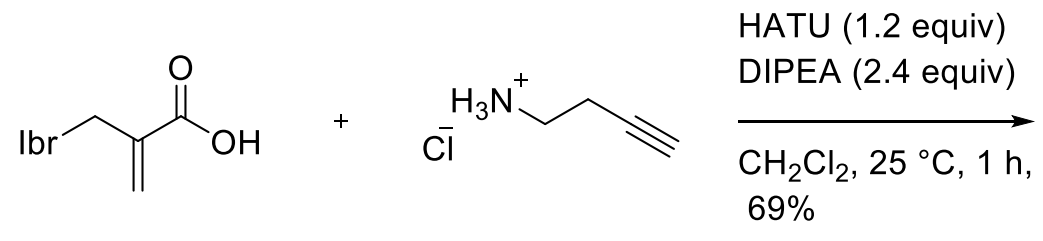

Ibr-acid

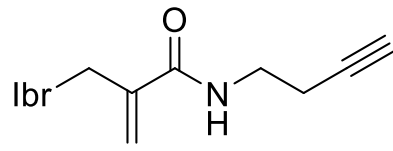

$1 \mathrm{~b}$

To a stirred solution of carboxylic acid $(23.5 \mathrm{mg}, 0.05 \mathrm{mmol})$ in $\mathrm{CH}_{2} \mathrm{Cl}_{2}(1 \mathrm{~mL})$, HATU (23 mg, 0.06 mmol), DIPEA (20.4 $\mu \mathrm{L}, 0.12 \mathrm{mmol})$ and but-3-yn-1-amine hydrochloride (6.3 mg, $0.06 \mathrm{mmol})$ were added at $25^{\circ} \mathrm{C}$. The reaction mixture was stirred at room temperature for $1 \mathrm{~h}$. After completion of the reaction (as monitored by LC-MS), water $(1 \mathrm{~mL})$ was added. The aqueous layer was extracted with $\mathrm{CH}_{2} \mathrm{Cl}_{2}(3 \times 3 \mathrm{~mL})$. The combined organic layer was concentrated in vacuo and the crude product was purified by preparative HPLC using water:ACN (0.1\% formic acid) solvent gradient to afford white solid $1 \mathbf{b}$ in $18 \mathrm{mg}$ (69\% yield).

${ }^{1}$ H NMR (400 MHz, CD ${ }_{3} \mathrm{OD}$ ): $\delta 2.09$ (br. s., 1H), 2.21 (br. s., 1H), 2.32 (br. s., 2H), 2.45 (br. s., 2H), 3.26 (br. s., 1H), 3.44 (br. s., 2H), 3.82 (d, $J=11.2 \mathrm{~Hz}, 2 \mathrm{H}), 4.12$ (d, $J=12.8 \mathrm{~Hz}, 2 \mathrm{H}), 4.26$ (d, $J=$ $13.0 \mathrm{~Hz}, 1 \mathrm{H}), 5.56$ (br. s., 1H), 6.14 (s, 1H), 6.35 (s, 1H), 7.21 (d, J=7.7 Hz, 2H), 7.28 (s, 3H), 7.487.56 (m, 2H), 7.98 (br. s., 2H), 8.52 (s, 1H): ${ }^{13}$ C NMR (100 MHz, $\left.\mathrm{CD}_{3} \mathrm{OD}\right): \delta$ 19.7, 28.4, 39.8, 52.0, 53.2, 55.6, 61.3, 71.2, 82.1, 98.8, 120.1, 120.9, 125.4, 127.1, 129.6, 131.3, 131.9, 133.7, 148.4, 152.0, 
153.9, 156.8, 157.9, 160.8, 169.1; HR-MS (m/z): Calculated for $\mathrm{C}_{30} \mathrm{H}_{32} \mathrm{~N}_{7} \mathrm{O}_{2}[\mathrm{M}+\mathrm{H}]^{+}: 522.2617$; Found $[\mathrm{M}+\mathrm{H}]^{+}: 522.2620$.

\section{(R)-2-((3-(4-amino-3-(4-phenoxyphenyl)-1H-pyrazolo[3,4-d]pyrimidin-1-yl)piperidin-1-} yl)methyl)-N-(4-ethynylphenyl)acrylamide (1c):<smiles>C=C(CBr)C(=O)O</smiles>

Ibr-acid

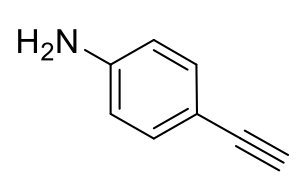

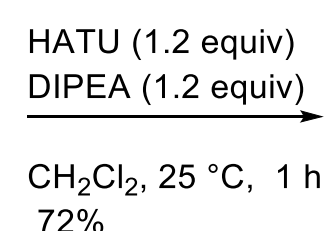

$72 \%$

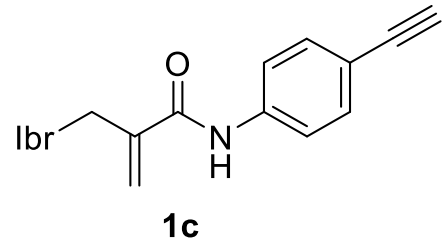

To a stirred solution of carboxylic acid $(23.5 \mathrm{mg}, 0.05 \mathrm{mmol})$ in $\mathrm{CH}_{2} \mathrm{Cl}_{2}(1 \mathrm{~mL})$, HATU ( $23 \mathrm{mg}, 0.06$ mmol), DIPEA (10.4 $\mu \mathrm{L}, 0.06 \mathrm{mmol})$ and 4-ethynylaniline (7.02 $\mathrm{mg}, 0.06 \mathrm{mmol})$ were added at 25 ${ }^{\circ} \mathrm{C}$. The reaction mixture was stirred at room temperature for $1 \mathrm{~h}$. After completion of the reaction (as monitored by LC-MS), water $(1 \mathrm{~mL})$ was added. The aqueous layer was extracted with $\mathrm{CH}_{2} \mathrm{Cl}_{2}(3 \times$ $3 \mathrm{~mL}$ ). The combined organic layer was concentrated in vacuo and the crude product was purified by preparative HPLC using water:ACN $(0.1 \%$ formic acid) solvent gradient to afford white solid $\mathbf{1 c}$ in $20.4 \mathrm{mg}$ ( $72 \%$ yield).

${ }^{1}$ H NMR (500 MHz, $\mathrm{CD}_{3} \mathrm{OD}$ ): $\delta$ ppm 2.00 (br. s., $1 \mathrm{H}$ ), 2.06-2.18 (m, 1H), 2.24 (br. s., $2 \mathrm{H}$ ), 3.22 (br. s., $1 \mathrm{H}), 3.51$ (s, 1H), 3.76 (d, $J=11.8 \mathrm{~Hz}, 1 \mathrm{H}), 3.85$ (br. s., $1 \mathrm{H}), 4.10$ (d, $J=12.8 \mathrm{~Hz}, 2 \mathrm{H}), 4.23$ (d, $J$ $=12.9 \mathrm{~Hz}, 1 \mathrm{H}), 5.48$ (br. s., $1 \mathrm{H}), 6.19$ (s, 1H), 6.47 (s, 1H), 7.13 (t, $J=8.2 \mathrm{~Hz}, 4 \mathrm{H}), 7.21$ (t, $J=7.4$ Hz, 1H), 7.36 (d, $J=7.8 \mathrm{~Hz}, 2 \mathrm{H}$ ), 7.43 (t, $J=7.8 \mathrm{~Hz}, 2 \mathrm{H}$ ), 7.53 (br. s., 2H), 7.82 (br. s., 2H), 8.39 (s, 1H); ${ }^{13}$ C NMR (125 MHz, $\left.\mathrm{CD}_{3} \mathrm{OD}\right): \delta$ ppm 20.1, 28.4, 36.3, 51.8, 53.4, 55.8, 61.4, 78.9, 84.3, 98.9, 120.0, 121.0, 121.5, 125.6, 127.2, 131.1, 131.4, 131.8, 133.8, 139.7, 148.1, 153.0, 154.1, 157.7, 160.8, 167.6. HR-MS (m/z): Calculated for $\mathrm{C}_{34} \mathrm{H}_{32} \mathrm{~N}_{7} \mathrm{O}_{2}:[\mathrm{M}+\mathrm{H}]^{+}: 570.6770$; Found $[\mathrm{M}+\mathrm{H}]^{+}: 570.6775$.

\section{Synthesis of pre-1d:}

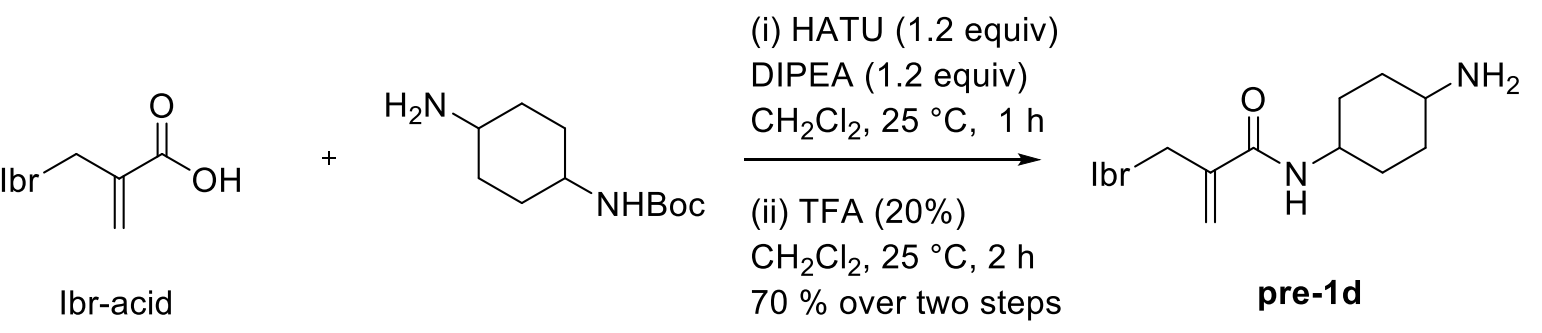

To a stirred solution of carboxylic acid ( $47 \mathrm{mg}, 0.1 \mathrm{mmol})$ in $\mathrm{CH}_{2} \mathrm{Cl}_{2}(5 \mathrm{~mL})$, HATU (45.6 mg, 0.12 mmol), DIPEA (20.9 $\mu \mathrm{L}, 0.12 \mathrm{mmol})$ and tert-butyl (4-aminocyclohexyl) carbamate $(25.6 \mathrm{mg}, 0.12$ 
mmol) were added at $25^{\circ} \mathrm{C}$. The reaction mixture was stirred at room temperature for $1 \mathrm{~h}$. After completion of the reaction (as monitored by LC-MS), $3 \mathrm{~mL}$ water was added. The aqueous layer was extracted with $\mathrm{CH}_{2} \mathrm{Cl}_{2}(3 \times 5 \mathrm{~mL})$. The combined organic layers were concentrated in vacuo and the crude product was dissolved in 20\% TFA in DCM and allowed to stir at $25^{\circ} \mathrm{C}$ for $2 \mathrm{~h}$. The reaction mixture was concentrated and purified by using flash column chromatography in ethyl acetate:methanol (7:3) solvent system to get pure amine in $39.6 \mathrm{mg}$ (yield $=70 \%$ ).

${ }^{1} \mathrm{H}$ NMR (400 MHz, CD $\left.{ }_{3} \mathrm{OD}\right): \delta 1.64$ (br. s., 3H), 1.94 - 2.06 (m, 2H), 2.10 (br. s., 3H), 2.25 (br. s., 3H), 2.82 (s, 1H), 2.94 - 3.04 (m, 2H), 3.08 (s, 1H), 3.41 (br. s., 1H), 3.47 (br. s., 1H), 3.77 (dd, $J=$ 12.9, 3.6Hz, 1H), 3.97 (d, $J=13.2 \mathrm{~Hz}, 2 \mathrm{H}), 4.15$ (d, $J=13.0 \mathrm{~Hz}, 1 \mathrm{H}), 4.24$ (br. s., $1 \mathrm{H}), 4.54$ (br. s., 1H), 5.36 (br. s., 1H), $5.81(\mathrm{~s}, 1 \mathrm{H}), 6.02(\mathrm{~s}, 1 \mathrm{H}), 7.03-7.24(\mathrm{~m}, 5 \mathrm{H}), 7.37-7.49(\mathrm{~m}, 2 \mathrm{H}), 7.79(\mathrm{~d}, J=$ $8.4 \mathrm{~Hz}, 2 \mathrm{H}), 8.32(\mathrm{~s}, 1 \mathrm{H}) ;{ }^{13} \mathbf{C}$ NMR (100 MHz, CD $\left.{ }_{3} \mathrm{OD}\right): \delta 28.8,30.7,39.0,56.0,61.7,99.2,119.9$, $120.7,122.1,125.4$, 128.2, 129.7, 131.3, 131.8, 136.4, 141.0, 146.9, 151.7, 154.8, 156.1, 158.0, 159.5, $160.3,170.1$.

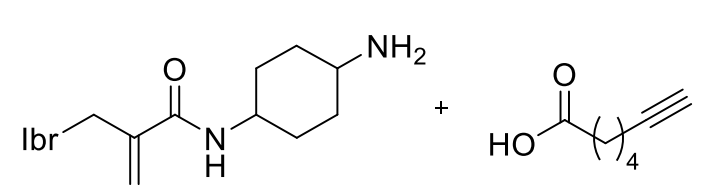

pre-1d

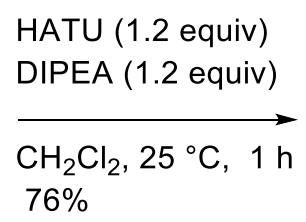

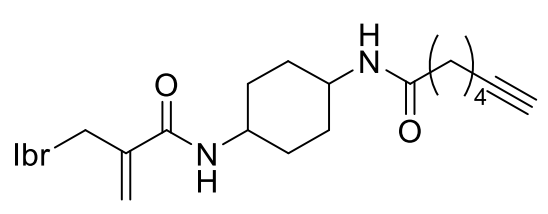

1d

To a stirred solution of carboxylic acid $(7.56 \mathrm{mg}, 0.06 \mathrm{mmol})$ in $\mathrm{CH}_{2} \mathrm{Cl}_{2}(5 \mathrm{~mL})$, HATU (23 mg, 0.06 mmol), DIPEA (10.4 $\mu \mathrm{L}, 0.06 \mathrm{mmol})$ and pre-1d $(28 \mathrm{mg}, 0.05 \mathrm{mmol})$ were added at $25^{\circ} \mathrm{C}$. The reaction mixture was stirred at room temperature for $1 \mathrm{~h}$. After completion of the reaction (as monitored by LC-MS), $1 \mathrm{~mL}$ water was added. The aqueous layer was extracted with $\mathrm{CH}_{2} \mathrm{Cl}_{2}(3 \times 3$ $\mathrm{mL})$. The combined organic layers were concentrated in vacuo and the crude product was purified by preparative HPLC using water:ACN (0.1\% TFA) solvent gradient to afford 1d in $25.6 \mathrm{mg}$ (yield $=76 \%$ ).

${ }^{1}$ H NMR (500 MHz, CD $\left.{ }_{3} \mathrm{OD}\right): \delta 1.33-1.48(\mathrm{~m}, 2 \mathrm{H}), 1.48-1.61(\mathrm{~m}, 3 \mathrm{H}), 1.66-1.80(\mathrm{~m}, 2 \mathrm{H}), 1.90$ (br. s., $2 \mathrm{H}), 1.94-2.11$ (m, 2H), 2.22 (br. s., $8 \mathrm{H}), 2.98$ (d, $J=14.4 \mathrm{~Hz}, 1 \mathrm{H}), 3.13$ (br. s., 1H), 3.18 (s, 1H), 3.62-3.79 (m, 1H), 3.79-4.00 (m, 3H), 4.09 (br. s., 2H), 4.12-4.22 (m, 1H), 4.37 (br. s., 1H), 5.43 (br. s., 1H), 5.82 (br. s., 1H), 6.01 (br. s., 1H), 7.12 (d, J=8.4 Hz, 2H), 7.17 (d, J=8.7 Hz, 2H), 7.23 (t, 
$J=7.4 \mathrm{~Hz}, 1 \mathrm{H}), 7.39-7.50$ (m, 2H), 7.86 (br. s., 2H), 8.37 (s, 1H); ${ }^{13} \mathbf{C}$ NMR (125 MHz, $\left.\mathrm{CD}_{3} \mathrm{OD}\right)$ : $\delta 17.4,18.5,24.7,27.8,30.8,31.7,35.1,40.5,46.3,54.4,60.4,68.4,83.2,97.6,102.7,118.3,118.6$, 119.4, 124.0, 129.8, 130.4, 153.8, 156.4, 159.1, 168.3, 173.9. HR-MS (m/z): Calculated for $\mathrm{C}_{39} \mathrm{H}_{47} \mathrm{~N}_{8} \mathrm{O}_{3}:[\mathrm{M}+\mathrm{H}]^{+}: 675.3771 ;$ Found $[\mathrm{M}+\mathrm{H}]^{+}: 675.3777$.

\section{(R)-2-((3-(4-amino-3-(4-phenoxyphenyl)-1H-pyrazolo[3,4-d]pyrimidin-1-yl)piperidin-1-} yl)methyl)-N-(2-aminoethyl)acrylamide (1e):
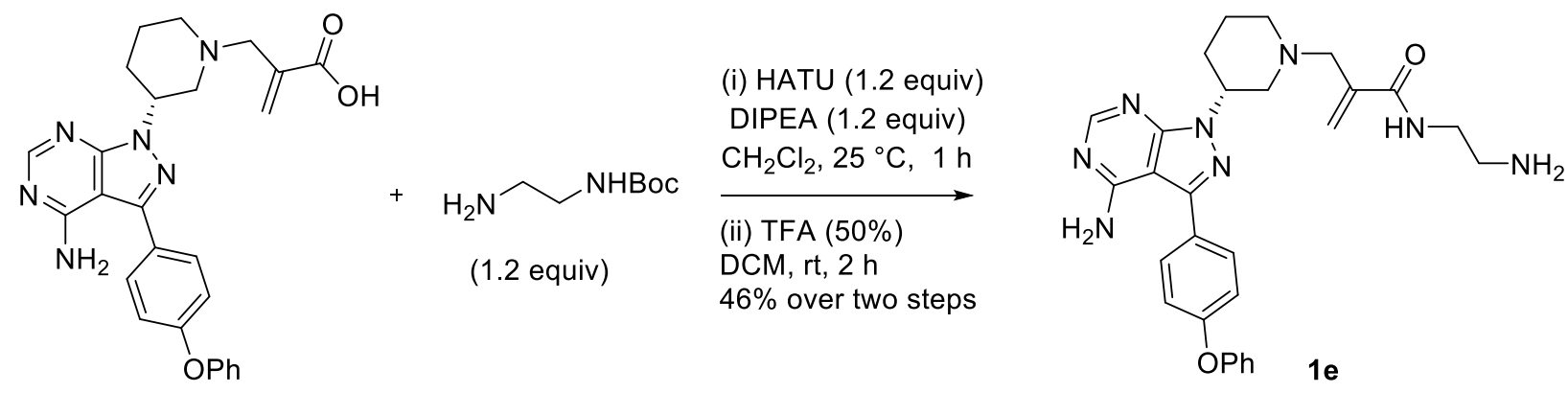

To a stirred solution of carboxylic acid (188 mg, $0.4 \mathrm{mmol}$ ) in $\mathrm{CH}_{2} \mathrm{Cl}_{2}(5 \mathrm{~mL})$, HATU (182 mg, 0.48 mmol), DIPEA ( $85 \mu \mathrm{L}, 0.48 \mathrm{mmol})$ and $N$-Boc ethelene diamine $(77 \mathrm{mg}, 0.48 \mathrm{mmol})$ were added at $25^{\circ} \mathrm{C}$. The reaction mixture was stirred at room temperature for $1 \mathrm{~h}$. After completion of the reaction (as monitored by LC-MS), $3 \mathrm{~mL}$ water was added. The aqueous layer was extracted with $\mathrm{CH}_{2} \mathrm{Cl}_{2}$ (3 $\times 5 \mathrm{~mL}$ ). The combined organic layers were concentrated in vacuo and the crude product was dissolved in 50\% TFA in DCM and allowed to stir at $25{ }^{\circ} \mathrm{C}$ for $2 \mathrm{~h}$. The reaction mixture was concentrated and purified by using flash column chromatography in ethyl acetate:methanol (7:3) solvent system to get pure amine 1e in $94 \mathrm{mg}$ (yield $=46.0 \%$ ).

${ }^{1}$ H NMR (400 MHz, CD 3 OD): $\delta 2.12$ (br. s., 2H), 2.35 (br. s., 2H), 3.10 (br. s., 0.5H), 3.16-3.24 (m, 2H), 3.34 (br. s., $0.5 \mathrm{H}$ ), 3.59-3.66 (m, 2H), 3.70-3.72 (m, 1H), 3.85 (br. s., $2 \mathrm{H}), 4.16$ (d, $J=12.8 \mathrm{~Hz}$, 1H), 4.27 (d, $J=12.8 \mathrm{~Hz}, 1 \mathrm{H}), 5.50$ (br. s., 1H), $6.22(\mathrm{~s}, 1 \mathrm{H}), 6.43$ (s, 1H), 7.21 (d, $J=7.7 \mathrm{~Hz}, 2 \mathrm{H})$, 7.25-7.35 (m, 3H), 7.49-7.57 (m, 2H), 7.88 (br. s., 2H), 8.51 (s, 1H); ${ }^{13} \mathrm{C}$ NMR (101 MHz, $\left.\mathrm{CD}_{3} \mathrm{OD}\right)$ $\delta$ 28.6, 38.6, 40.5, 40.9, 52.7, 53.3, 55.4, 60.7, 98.9, 116.7, 119.6, 120.1, 120.8, 125.5, 127.5, 128.4, 130.8, 131.3, 131.7, 133.9, 135.5, 148.1, 154.2, 157.9, 160.7, 169.7. HR-MS (m/z): Calculated for $\mathrm{C}_{28} \mathrm{H}_{33} \mathrm{~N}_{8} \mathrm{O}_{2}[\mathrm{M}+\mathrm{H}]^{+}:$513.2726; Found $[\mathrm{M}+\mathrm{H}]^{+}: 513.2722$. 


\section{Synthesis of 1f:}

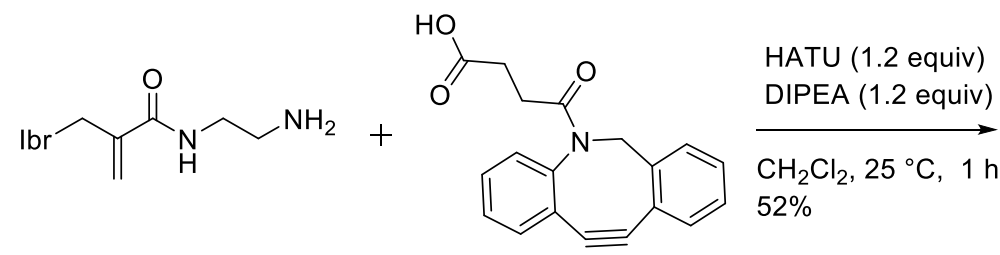

$1 \mathrm{e}$

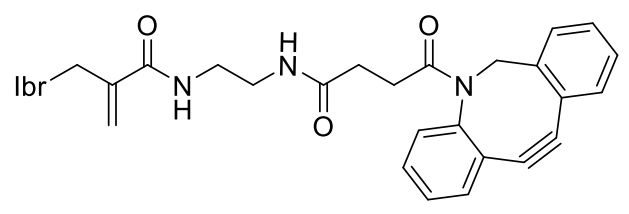

$1 f$

To a stirred solution of DBCO carboxylic acid ( $7.6 \mathrm{mg}, 0.025 \mathrm{mmol})$ in $\mathrm{CH}_{2} \mathrm{Cl}_{2}$ (1 mL), HATU (11.5 mg, $0.03 \mathrm{mmol})$, DIPEA $(5.2 \mu \mathrm{L}, 0.03 \mathrm{mmol})$ and amine 1e (13 mg, $0.05 \mathrm{mmol})$ were added at 25 ${ }^{\circ} \mathrm{C}$. The reaction mixture was stirred at room temperature for $1 \mathrm{~h}$. After completion of the reaction (as monitored by LC-MS), the reaction mixture was quenched with $\mathrm{H}_{2} \mathrm{O}(1 \mathrm{~mL})$. The aqueous layer was extracted with $\mathrm{CH}_{2} \mathrm{Cl}_{2}(3 \times 1 \mathrm{~mL})$ and the combined organic layers were evaporated under vacuo. The crude product was purified by preparative HPLC using water:ACN $(0.1 \%$ TFA) solvent gradient to afford DBCO alkyne $1 \mathbf{f}$ as colorless solid in $10.3 \mathrm{mg}$ (yield $=52 \%$ ).

*15\% of the 1d was hydrolyzed at DBCO amide site during HPLC purification.

${ }^{1}$ H NMR (500 MHz, CD $30 D$ ): $\delta 1.94$ (br. s., 2H), 2.08 (br. s., 2H), 2.21 (br. s., 3H), 2.61-2.72 (m, 1H), 3.02-3.19 (m, 3H), 3.70 (d, $J=14.0$ Hz, 2H), 3.76 (br. s., 1H), 3.99 (br. s., 1H), 4.07 (br. s., 1H), 4.15 (br. s., 1H), 5.09 (d, $J=14.0$ Hz, 1H), 5.44 (br. s., 1H), 6.00 (br. s., 1H), 6.18 (s, 1H), 7.11 (d, $J$ $=7.8 \mathrm{~Hz}, 2 \mathrm{H}), 7.16(\mathrm{~d}, J=8.5 \mathrm{~Hz}, 2 \mathrm{H}), 7.18-7.26(\mathrm{~m}, 2 \mathrm{H}), 7.32$ (br. s., $2 \mathrm{H}), 7.39-7.52(\mathrm{~m}, 5 \mathrm{H}), 7.56$ (d, $J=7.3 \mathrm{~Hz}, 1 \mathrm{H}), 7.61$ (br. s., $1 \mathrm{H}), 7.86$ (br. s., $1 \mathrm{H}), 8.41$ (br. s., $1 \mathrm{H}) ;{ }^{13} \mathbf{C}$ NMR $\left(126 \mathrm{MHz}, \mathrm{CD}_{3} \mathrm{OD}\right)$ : $\delta 20.0,28.4,31.4,32.0,40.6,52.0,53.1,55.7,56.9,101.5,108.9,120.0,120.9,123.9,124.5,125.5$, $126.7,128.3,129.0,129.3,129.9,130.2,130.7,131.3,132.0,133.5,149.7,152.7,157.9,160.7,174.2$, 177.2; HR-MS (m/z): Calculated for $\mathrm{C}_{47} \mathrm{H}_{46} \mathrm{~N}_{9} \mathrm{O}_{4}[\mathrm{M}+\mathrm{H}]^{+}:$: 800.3673; Found $[\mathrm{M}+\mathrm{H}]^{+}:$800.3684.

\section{(R)-2-((3-(4-amino-3-(4-phenoxyphenyl)-1H-pyrazolo[3,4-d]pyrimidin-1-yl)piperidin-1-} yl)methyl)-N-(2-(3-(3',6'-dihydroxy-3-oxo-3H-spiro[isobenzofuran-1,9'-xanthen]-5yl)thioureido)ethyl)acrylamide (1g):
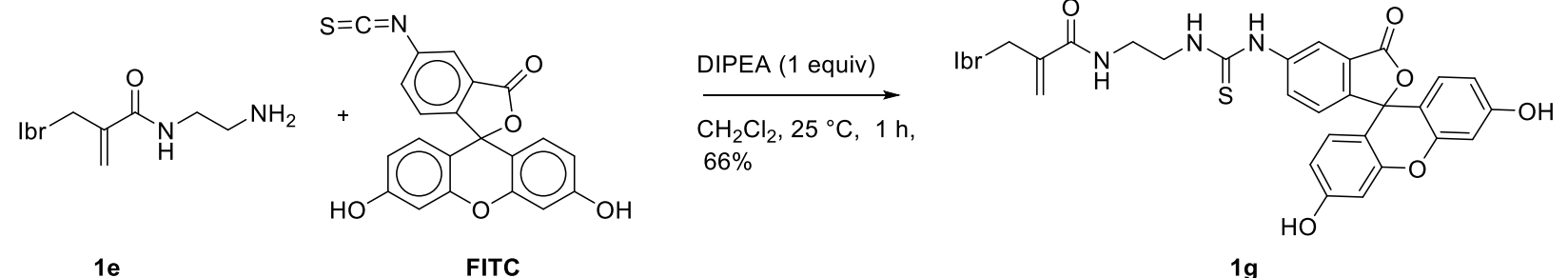
To a stirred solution of 1 e $(0.05 \mathrm{mmol}, 26 \mathrm{mg})$ in anhydrous DCM $(1 \mathrm{~mL})$, DIPEA $(9 \mu \mathrm{L}, 0.05 \mathrm{mmol})$ and FITC (19 mg, $0.05 \mathrm{mmol})$ were added at $25^{\circ} \mathrm{C}$. The reaction mixture was stirred at room temperature for $1 \mathrm{~h}$. After completion of the reaction (as monitored by LC-MS), the reaction mixture was quenched with $\mathrm{H}_{2} \mathrm{O}(2 \mathrm{~mL})$. The aqueous layer was extracted with $\mathrm{CH}_{2} \mathrm{Cl}_{2}(3 \times 2 \mathrm{~mL})$ evaporated under vacuo. The crude product was purified by preparative HPLC using water:ACN (0.1\% TFA) solvent gradient to afford $\mathbf{1 g}$ as yellow color solid in $29.1 \mathrm{mg}$ (yield $=66 \%$ ).

${ }^{1}$ H NMR (400 MHz, CD 3 OD): $\delta 1.83$ (br. s., 2H), 2.15 (br. s., 2H), 3.12 (d, J=12.8 Hz, 1H), 3.39 (br. s., 1H), 3.54-3.78 (m, 4H), 4.00 (br. s., 3H), 4.19 (m, 1H), 5.42 (br. s., 1H), 6.07 (s, 1H), 6.35 (s, 1H), 6.47 (br. s., 1H), 6.51-6.59 (m, 2H), 6.64 (s, 1H), 6.67 (s, 1H), 6.72 (d, J=2.2 Hz, 1H), 6.84 (br. s., $1 \mathrm{H}), 7.08(\mathrm{t}, J=9.0 \mathrm{~Hz}, 4 \mathrm{H}), 7.19$ (t, $J=7.5 \mathrm{~Hz}, 1 \mathrm{H}), 7.36-7.46(\mathrm{~m}, 2 \mathrm{H}), 7.71(\mathrm{~d}, J=8.1 \mathrm{~Hz}, 1 \mathrm{H})$, 7.78 (br. s., 2H), 7.95 (br. s., $1 \mathrm{H}), 8.41$ (br. s., $1 \mathrm{H}) ;{ }^{13} \mathbf{C}$ NMR (100 MHz, $\left.\mathrm{CD}_{3} \mathrm{OD}\right): \delta 19.9,28.3,40.8$, 45.0, 51.9, 53.0, 55.8, 61.4, 98.7, 103.7, 111.9, 114.2, 114.3, 119.9, 120.0, 121.0, 125.5, 126.4, 129.4, 130.5, 130.7, 131.3, 132.0, 133.6, 142.1, 148.1, 152.6, 154.0, 154.6, 157.0, 157.7, 160.9, 162.2, 162.3, 169.2, 170.9, 183.2. HR-MS (m/z): Calculated for $\mathrm{C}_{49} \mathrm{H}_{44} \mathrm{~N}_{9} \mathrm{O}_{7} \mathrm{~S}[\mathrm{M}+\mathrm{H}]^{+}$: 902.3084 ; Found $[\mathrm{M}+\mathrm{H}]^{+}$: 902.3082 .

\section{(R)-2-((3-(4-amino-3-(4-phenoxyphenyl)-1H-pyrazolo[3,4-d]pyrimidin-1-yl)piperidin-1-} yl)methyl)-N-(2-(2-((9-(diethylamino)-5-0xo-5H-benzo[a]phenoxazin-2-

yl)oxy)acetamido)ethyl)acrylamide (1h):

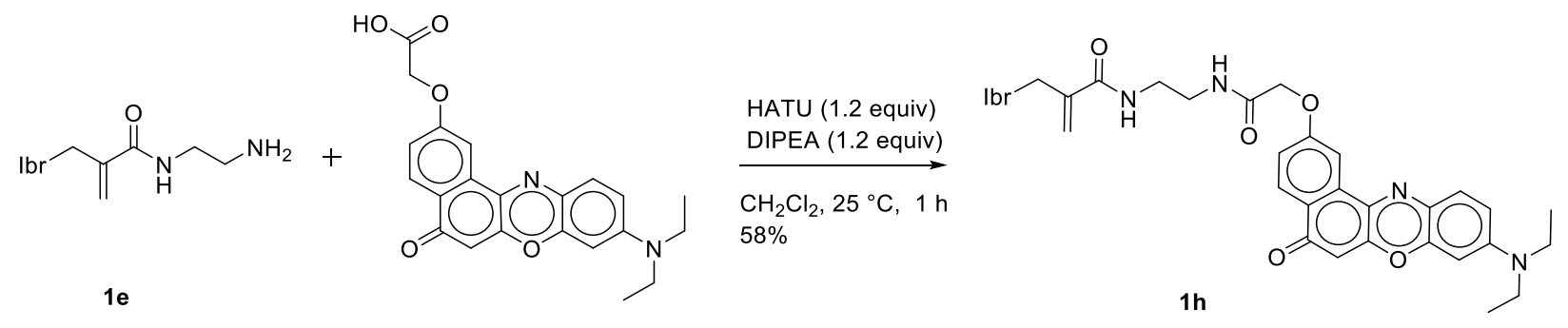

To a stirred solution of carboxylic acid (Nile Red carboxylic acid was synthesized using the literature report $\left.^{2}, 19 \mathrm{mg}, 0.05 \mathrm{mmol}\right)$ in $\mathrm{CH}_{2} \mathrm{Cl}_{2}(1 \mathrm{~mL})$, HATU $(23 \mathrm{mg}, 0.06 \mathrm{mmol})$, DIPEA (10.4 $\mu \mathrm{L}, 0.06$ mmol) and amine 1e $(13 \mathrm{mg}, 0.05 \mathrm{mmol})$ were added at $25^{\circ} \mathrm{C}$. The reaction mixture was stirred at room temperature for $1 \mathrm{~h}$. After completion of the reaction (as monitored by LC-MS), the reaction mixture was quenched with $\mathrm{H}_{2} \mathrm{O}(2 \mathrm{~mL})$. The aqueous layer was extracted with $\mathrm{CH}_{2} \mathrm{Cl}_{2}(3 \times 3 \mathrm{~mL})$ evaporated under vacuo. The crude product was purified by preparative HPLC using water:ACN ( $0.1 \%$ TFA) solvent gradient to afford $\mathbf{1 h}$ as blue colour solid in $25.7 \mathrm{mg}$ (yield $=58 \%$ ).

${ }^{1}$ H NMR (500 MHz, CD $\left.{ }_{3} \mathrm{OD}\right): \delta 1.29$ (t, $\left.J=6.6 \mathrm{~Hz}, 6 \mathrm{H}\right), 1.91$ (br. s., 2H), 2.12 (br. s., 2H), 3.10 (br. 
s., 1H), 3.47 (br. s., 4H), 3.57 (d, $J=6.2 \mathrm{~Hz}, 5 \mathrm{H}), 3.71$ (br. s., $2 \mathrm{H}), 3.92-4.10$ (m, 2H), 4.19 (d, $J=$ $12.5 \mathrm{~Hz}, 1 \mathrm{H}), 4.57$ (br. s., 1H), 5.29 (br. s., 1H), 6.05 (br. s., 1H), 6.20 (d, J=8.5 Hz, 1H), 6.24 (br. s., 1H), 6.62 (d, $J=8.3 \mathrm{~Hz}, 1 \mathrm{H}), 6.88$ (br. s., 1H), 7.09 (d, $J=7.0 \mathrm{~Hz}, 4 \mathrm{H}), 7.14-7.19$ (m, 1H), 7.21 (br. s., 1H), 7.42 (t, $J=7.5$ Hz, 2H), 7.56 (br. s., 2H), 7.75 (br. s., 2H), 7.91 (d, $J=12.9$ Hz, 1H), 8.03 (br. s., 1H), 8.29 (br. s., 1 H); ${ }^{13}$ C NMR (126 MHz, CD3OD $\delta$ ppm 13.0, 19.9, 28.4, 40.5, 40.8, 46.4, 52.2, 52.2, 52.9, 55.6, 61.5, 68.4, 97.4, 98.7, 104.8, 108.2, 112.6, 119.0, 119.9, 120.9, 125.5, 126.8, 127.0, 128.7, 129.7, 131.3, 131.9, 132.7, 135.5, 138.6, 148.7, 153.6, 154.1, 157.8, 160.7, 161.7, 169.6, 184.0.; HR-MS (m/z): Calculated for $\mathrm{C}_{50} \mathrm{H}_{51} \mathrm{~N}_{10} \mathrm{O}_{6}[\mathrm{M}+\mathrm{H}]^{+}:$887.3993; Found $[\mathrm{M}+\mathrm{H}]^{+}$: 887.3994.

(S)-2-((3-(4-amino-3-(4-phenoxyphenyl)-1H-pyrazolo[3,4-d]pyrimidin-1-yl)piperidin-1-yl)methyl)N-(2-(3-(5,5-difluoro-7,9-dimethyl-5H-514,614-dipyrrolo[1,2-c:2',1'-f][1,3,2]diazaborinin-3yl)propanamido)ethyl)acrylamide (1i)

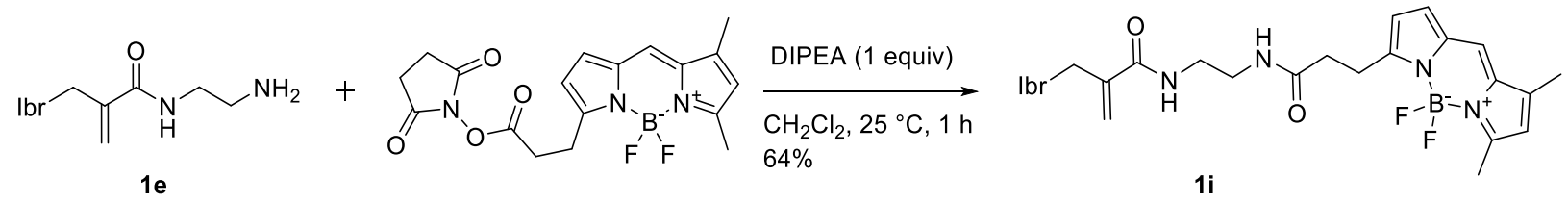

To a stirred solution of $1 \mathrm{e}(6.4 \mathrm{mg}, 0.0125 \mathrm{mmol})$ in $\mathrm{CH}_{2} \mathrm{Cl}_{2}(0.5 \mathrm{~mL})$, BODIPY NHS ester (4.9 mg, $0.0125 \mathrm{mmol})$, DIPEA $(2.2 \mu \mathrm{L}, 0.0125 \mathrm{mmol})$ were added at $25^{\circ} \mathrm{C}$. The reaction mixture was stirred at room temperature for $1 \mathrm{~h}$. After completion of the reaction (as monitored by LC-MS), the reaction mixture was concentrated under vacuo and the crude product was purified by preparative HPLC using water:ACN (0.1\% TFA) solvent gradient to afford $1 \mathbf{i}$ as bright yellow colour solid in $6.2 \mathrm{mg}$ (yield= $64 \%)$.

${ }^{1}$ H NMR (400 MHz, CD $\left.3 \mathrm{OD}\right): \delta 1.32-1.37$ (m, 2H), 1.85-2.02 (br. s., 2H), 2.21 (d, J=7.5 Hz, 2H), 2.28 (s, 3H), 2.46 (br. s., $4 \mathrm{H}), 3.10$ (t, $J=7.7 \mathrm{~Hz}, 2 \mathrm{H}), 3.14$ (dt, $J=3.3,1.7 \mathrm{~Hz}, 1 \mathrm{H}), 3.49$ (dt, $J=3.2$, $1.7 \mathrm{~Hz}, 1 \mathrm{H}), 3.58-3.73(\mathrm{~m}, 3 \mathrm{H}), 3.77(\mathrm{~s}, 1 \mathrm{H}), 3.95-4.03(\mathrm{~m}, 1 \mathrm{H}), 4.03-4.11(\mathrm{~m}, 1 \mathrm{H}), 4.15(\mathrm{~d}, J=12.8$ Hz, 1H), 5.36-5.46 (m, 1H), 6.02 (s, 1H), 6.21 (s, 2H), 6.25 (br. s., 1H), 6.96 (br. s., 1H), 7.11 (d, J= $7.7 \mathrm{~Hz}, 2 \mathrm{H}), 7.18$ (d, $J=9.5 \mathrm{~Hz}, 2 \mathrm{H}), 7.20-7.25$ (m, 1H), 7.35-7.50 (m, 3H), 7.52-7.64 (m, 1H), 7.80 - 7.92 (m, 1H), 8.38 (br. s., $1 \mathrm{H}) ;{ }^{13} \mathbf{C}$ NMR (100 MHz, $\left.\mathrm{CD}_{3} \mathrm{OD}\right): \delta 11.3,15.0,20.0,25.7,28.4,36.1$, 41.0, 52.1, 53.2, 55.5, 61.2, 117.5, 120.0, 120.9, 121.6, 125.5, 125.9, 127.4, 129.7, 131.3, 132.0, $134.9,136.7,140.5,146.2,153.5,154.2,157.9,158.4,160.7,161.6,169.3,175.2 ;$ HR-MS (m/z): Calculated for $\mathrm{C}_{42} \mathrm{H}_{46} \mathrm{BF}_{2} \mathrm{~N}_{10} \mathrm{O}_{3}[\mathrm{M}+\mathrm{H}]^{+}$: 787.3815; Found $[\mathrm{M}+\mathrm{H}]^{+}$: 787.3828 . 
Synthesis of 1j:

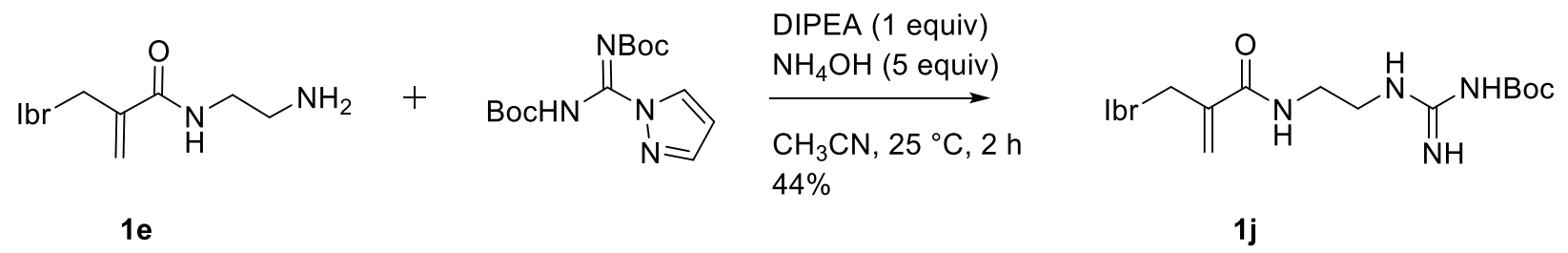

To a stirred solution of amine ( $26 \mathrm{mg}, 0.05 \mathrm{mmol})$ in anhydrous ACN $(1 \mathrm{~mL})$, DIPEA ( $8.5 \mu \mathrm{L}, 0.05$ mmol) and N, N'-Di Boc-1H-pyrazole-1-carboxamidine (18.6 mg, $0.06 \mathrm{mmol})$ and $\mathrm{NH}_{4} \mathrm{OH}(28 \%$ in water, $31 \mu \mathrm{L}$ ) were added at $25{ }^{\circ} \mathrm{C}$. The reaction mixture was stirred at room temperature for $2 \mathrm{~h}$. After completion of the reaction (as monitored by LC-MS), the reaction mixture was evaporated under vacuo. The crude product was purified by preparative HPLC using water:ACN $(0.1 \%$ TFA) solvent gradient to afford methacrylamide $(\mathbf{1} \mathbf{j})$ as colorless solid in $14.4 \mathrm{mg}$ (yield $=44 \%$ ). One of the Boc group was hydrolyzed in HPLC during purification.

${ }^{1} \mathbf{H}$ NMR (400 MHz, $\mathrm{CD}_{3} \mathrm{OD}$ ): $\delta 1.56$ (br. s., 9H), 2.09 (br. s., 2H), 2.34 (br. s., 2H), 3.20-3.25 (m, 1H), 3.47-3.65 (m, 5H), 3.82 (d, $J=9.2 \mathrm{~Hz}, 2 \mathrm{H}), 4.09-4.18$ (m, 1H), 4.27 (d, $J=12.3 \mathrm{~Hz}, 1 \mathrm{H}), 5.49$ (br. s., 1H), 6.20 (br. s., 1H), 6.39 (s, 1H), 7.21 (d, $J=7.7$ Hz, 2H), 7.24-7.34 (m, 3H), 7.47-7.59 (m, 2H), 7.91 (br. s., 2H), 8.48 (s, 1H). ${ }^{13} \mathbf{C}$ NMR (100 MHz, $\left.\mathrm{CD}_{3} \mathrm{OD}\right): \delta$ 26.7, 27.1, 37.4, 38.3, 40.2, 40.7, 51.0, 51.7, 54.1, 59.3, 84.5, 97.5, 118.5, 119.2, 123.9, 126.3, 128.9, 129.8, 130.3, 148.8, 152.1, 153.0, 154.4, 156.4, 159.0, 167.9, 168.2; HR-MS (m/z): Calculated for $\mathrm{C}_{34} \mathrm{H}_{43} \mathrm{~N}_{10} \mathrm{O}_{4}[\mathrm{M}+\mathrm{H}]^{+}$: 655.3469; Found $[\mathrm{M}+\mathrm{H}]^{+}: 655.3473$.

(R)-N-(2-(2-((3-(4-amino-3-(4-phenoxyphenyl)-1H-pyrazolo[3,4-d]pyrimidin-1-yl)piperidin-1yl)methyl)acrylamido)ethyl)-4-formylbenzamide (1k)

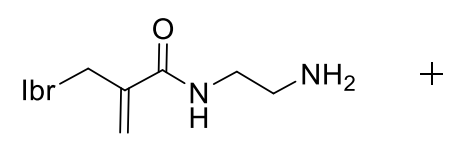

$1 e$<smiles>O=Cc1ccc(C(=O)O)cc1</smiles>

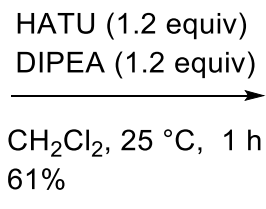

$61 \%$

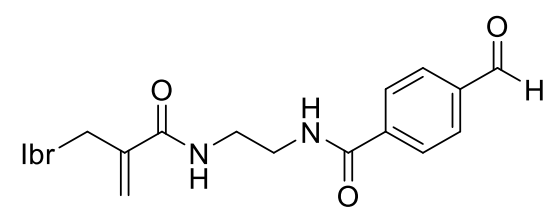

$1 k$

To a stirred solution of carboxylic acid ( $7.5 \mathrm{mg}, 0.05 \mathrm{mmol})$ in $\mathrm{CH}_{2} \mathrm{Cl}_{2}(1 \mathrm{~mL})$, HATU ( $23 \mathrm{mg}, 0.06$ mmol), DIPEA ( $10.4 \mu \mathrm{L}, 0.06 \mathrm{mmol})$ and amine $1 \mathrm{e}(26 \mathrm{mg}, 0.05 \mathrm{mmol})$ were added at $25^{\circ} \mathrm{C}$. The reaction mixture was stirred at room temperature for $1 \mathrm{~h}$. After completion of the reaction (as monitored by LC-MS), the reaction mixture was quenched with $\mathrm{H}_{2} \mathrm{O}(2 \mathrm{~mL})$. The aqueous layer was extracted with $\mathrm{CH}_{2} \mathrm{Cl}_{2}(3 \times 3 \mathrm{~mL})$ evaporated under vacuo. The crude product was purified by 
preparative HPLC using water:ACN (0.1\% TFA) solvent gradient to afford $1 \mathbf{k}$ as colorless solid in $19.64 \mathrm{mg}$ (yield $=61 \%$ ). ${ }^{*}$ Compound $1 \mathbf{k}$ formed an adduct with $\mathrm{CD}_{3} \mathrm{OD}(40 \%)$ during the NMR acquisition.

${ }^{1}$ H NMR (500 MHz, CD 3 OD): $\delta$ 1.24-1.44 (m, 2H), 1.89 (br. s., 2H), 2.20 (br. s., 3H), 3.10 (br. s., 1H), 3.19 (br. s., 1H), 3.47 (br. s., 1H), 3.52 (br. s., 3H), 3.60-3.78 (m, 2H), 3.96 (d, J = 12.4 Hz, 1H), 4.07 (d, $J=11.0 \mathrm{~Hz}, 1 \mathrm{H}), 4.18$ (d, $J=12.4 \mathrm{~Hz}, 1 \mathrm{H}), 5.35$ (br. s., 1H), 5.41 (br. s., 1H), 6.04 (br. s., 1H), 6.25 (br. s., 1H), 7.11 (br. s., 2H), 7.19 (br. s., 3H), 7.34-7.52 (m, 4H), 7.72 (br. s., 2H), 7.86 (br. s., $2 \mathrm{H}), 8.40$ (br. s., $1 \mathrm{H}) ;{ }^{13} \mathrm{C}$ NMR (126 MHz, CD $\left.\mathrm{OD}\right): \delta$ 18.4, 26.8, 39.3, 50.6, 51.3, 54.1, 59.7, $97.4,102.5,118.5,119.3,123.9,125.9,126.5,126.8,127.6,128.1,129.2,129.7,130.5,134.2,141.8$, 151.9, 152.7, 156.4, 159.2, 167.9, 168.7, 192.0; HR-MS (m/z): Calculated for $\mathrm{C}_{36} \mathrm{H}_{37} \mathrm{~N}_{8} \mathrm{O}_{4}[\mathrm{M}+\mathrm{H}]^{+}$: 645.2938; Found $[\mathrm{M}+\mathrm{H}]^{+}: 645.2941$.

(3R,5R,7R)-N-(2-(2-(((R)-3-(4-amino-3-(4-phenoxyphenyl)-1H-pyrazolo[3,4-d]pyrimidin-1-yl)piperidin1-yl)methyl)acrylamido)ethyl)adamantane-1-carboxamide (1I)<smiles>C=C(CBr)C(=O)NCCN</smiles>

$1 e$

(1)

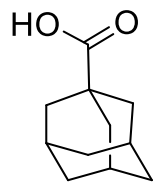

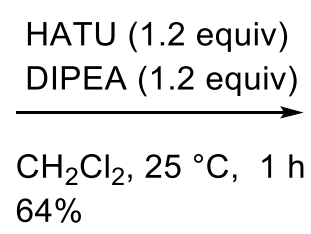

$64 \%$

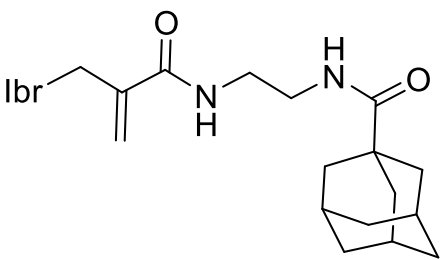

11

To a stirred solution of adamantane carboxylic acid ( $9 \mathrm{mg}, 0.05 \mathrm{mmol})$ in $\mathrm{CH}_{2} \mathrm{Cl}_{2}(1 \mathrm{~mL})$, HATU (23 mg, $0.06 \mathrm{mmol})$, DIPEA (10.4 $\mu \mathrm{L}, 0.06 \mathrm{mmol})$ and amine 1c $(26 \mathrm{mg}, 0.05 \mathrm{mmol})$ were added at 25 ${ }^{\circ} \mathrm{C}$. The reaction mixture was stirred at room temperature for $1 \mathrm{~h}$. After completion of the reaction (as monitored by LC-MS), the reaction mixture was quenched with $\mathrm{H}_{2} \mathrm{O}(2 \mathrm{~mL})$. The aqueous layer was extracted with $\mathrm{CH}_{2} \mathrm{Cl}_{2}(3 \times 3 \mathrm{~mL})$ evaporated under vacuo. The crude product was purified by preparative HPLC using water:ACN (0.1\% TFA) solvent gradient to afford $\mathbf{1 1}$ as colorless solid in $21.5 \mathrm{mg}($ yield $=64 \%)$.

${ }^{1}$ H NMR (400 MHz, CD 3 OD) $\delta 1.31$ (s, 3H), 1.57-1.69 (m, 3H), 1.72 (br. s., 2H), 1.77 (br. s., 7H), 1.89-2.00 (m, 3H), 2.16-2.25 (m, 2H), 2.28 (br. s., 1H), 3.08-3.21 (m, 1H), 3.38-3.46 (m, 2H), 3.70 $(\mathrm{d}, J=10.1 \mathrm{~Hz}, 1 \mathrm{H}), 3.79$ (d, $J=11.2 \mathrm{~Hz}, 1 \mathrm{H}), 3.96-4.13(\mathrm{~m}, 2 \mathrm{H}), 4.18$ (d, $J=13.0 \mathrm{~Hz}, 1 \mathrm{H}), 5.38-$ 5.49 (m, 1H), 6.06 (br. s., 1H), 6.23 (s, 1H), 7.12 (d, $J=8.8$ Hz, 1H), 7.16-7.28 (m, 2H), 7.39-7.49 $(\mathrm{m}, 2 \mathrm{H}), 7.69(\mathrm{~d}, J=8.6 \mathrm{~Hz}, 1 \mathrm{H}), 7.90(\mathrm{~d}, J=8.1 \mathrm{~Hz}, 1 \mathrm{H}), 8.37(\mathrm{~s}, 1 \mathrm{H}) ;{ }^{13} \mathbf{C} \mathbf{N M R}(126 \mathrm{MHz}, \mathrm{CDCl} 3)$ : 
$\delta 28.0,36.3,39.0,40.7,41.5,50.9,97.2,114.2,116.5,119.1,120.0,124.4,124.7,130.2,146.6,147.9$, 151.8, 153.4, 155.5, 160.1, 160.8, 161.1, 181.0. HR-MS (m/z): Calculated for $\mathrm{C}_{39} \mathrm{H}_{47} \mathrm{~N}_{8} \mathrm{O}_{3}[\mathrm{M}+\mathrm{H}]^{+}$: 675.3771; Found $[\mathrm{M}+\mathrm{H}]^{+}: 675.3775$.

tert-butyl (R)-(15-((3-(4-amino-3-(4-phenoxyphenyl)-1H-pyrazolo[3,4-d]pyrimidin-1yl)piperidin-1-yl)methyl)-9,14-dioxo-3,6-dioxa-10,13-diazahexadec-15-en-1-yl)carbamate (1m)
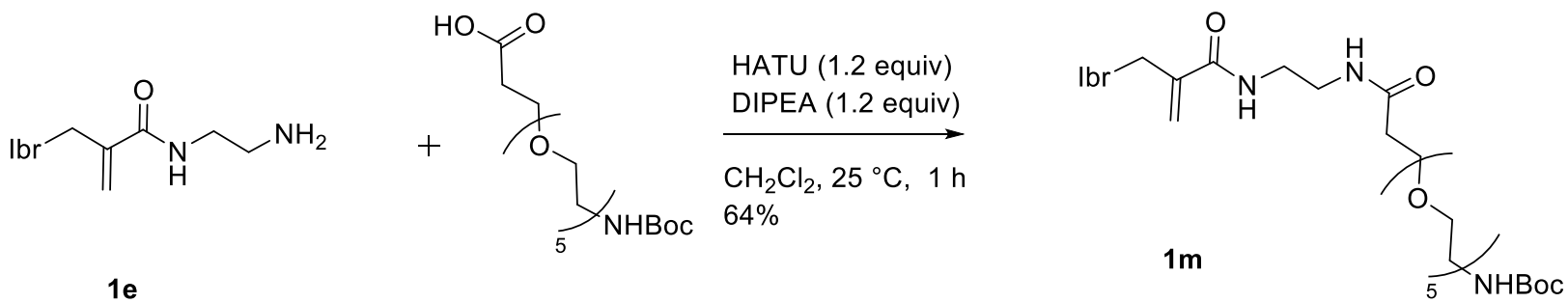

To a stirred solution of carboxylic acid (10.4 mg, 0.05mmol) in $\mathrm{CH}_{2} \mathrm{Cl}_{2}(1 \mathrm{~mL})$, HATU (23 mg, 0.06 mmol), DIPEA $(10.4 \mu \mathrm{L}, 0.06 \mathrm{mmol})$ and amine $1 \mathrm{e}(26 \mathrm{mg}, 0.05 \mathrm{mmol})$ were added at $25^{\circ} \mathrm{C}$. The reaction mixture was stirred at room temperature for $1 \mathrm{~h}$. After completion of the reaction (as monitored by LC-MS), the reaction mixture was quenched with $\mathrm{H}_{2} \mathrm{O}(2 \mathrm{~mL})$. The aqueous layer was extracted with $\mathrm{CH}_{2} \mathrm{Cl}_{2}(3 \times 2 \mathrm{~mL})$ evaporated under vacuo and the crude product was purified by preparative HPLC using water:ACN $(0.1 \%$ TFA) solvent gradient to afford $\mathbf{1 m}$ as colorless solid in $25.2 \mathrm{mg}$ (yield = $64 \%$ ).

${ }^{1}$ H NMR (500 MHz, CD $\left.{ }_{3} \mathrm{OD}\right): \delta 1.44$ (s, 11H), 1.99 (br. s., 1H), 2.12 (br. s., 1H), 2.24 (br. s., 2H), 2.39 (br. s., 2H), 3.19-3.23 (m, 3H), 3.49 (t, $J=5.6 \mathrm{~Hz}, 3 \mathrm{H}), 3.57-3.63$ (m, 17H), 3.65-3.70 (m, 4H), 3.82 (br. s., 1H), 4.04 (br. s., 1H), 4.07-4.14 (m, 1H), 4.18 (d, J=12.9 Hz, 1H), 5.48 (br. s., 1H), 6.04 (br. s., 1H), 6.25 (s, 1H), $7.14(\mathrm{~d}, J=8.0 \mathrm{~Hz}, 2 \mathrm{H}), 7.18-7.25(\mathrm{~m}, 3 \mathrm{H}), 7.45$ (t, $J=7.8 \mathrm{~Hz}, 2 \mathrm{H}), 7.92$ (br. s., 1H), 8.42 (s, 1H). ${ }^{13}$ C NMR (126 MHz, CD $\left.{ }_{3} \mathrm{OD}\right): \delta$ 20.1, 28.4, 28.9, 37.8, 39.6, 41.1, 41.4, 52.0, 53.2, 55.7, 61.3, 68.3, 71.2, 71.3, 71.4, 71.6, 71.6, 71.7, 71.7, 80.2, 99.0, 120.1, 120.9, 125.5, 127.6, 129.6, 131.3, 132.1, 133.9, 153.9, 154.5, 158.0, 158.6, 160.7, 169.1, 174.6; HR-MS (m/z): Calculated for $\mathrm{C}_{41} \mathrm{H}_{57} \mathrm{~N}_{8} \mathrm{O}_{8}[\mathrm{M}+\mathrm{H}]^{+}:$789.4299; Found $[\mathrm{M}+\mathrm{H}]^{+}:$789.4295. dione (pre-1n): 

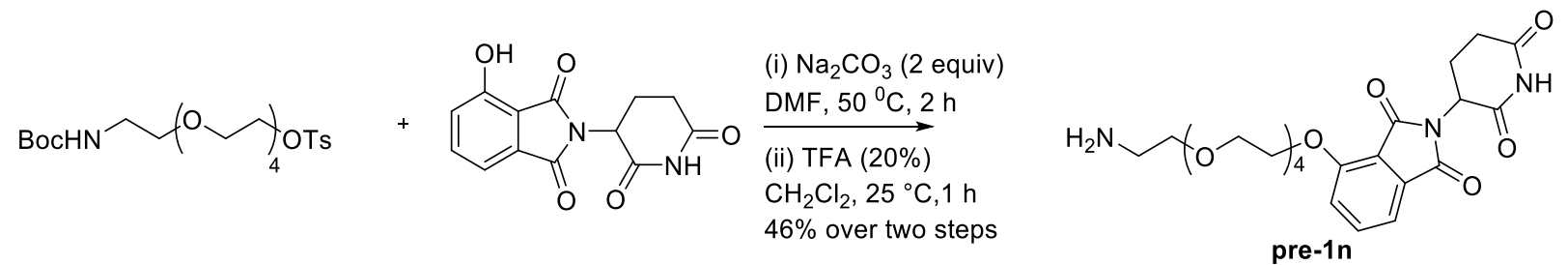

To a stirred solution of hydroxyl thalidomide ( $54.8 \mathrm{mg}, 0.2 \mathrm{mmol}$ ) in dry DMF (1 mL), $\mathrm{Na}_{2} \mathrm{CO}_{3}(42$ $\mathrm{mg}, 0.4 \mathrm{mmol})$ and tosyl compound $(78 \mathrm{mg}, 0.2 \mathrm{mmol})$ were added at $25^{\circ} \mathrm{C}$. The reaction mixture was stirred at $50{ }^{\circ} \mathrm{C}$ for $3 \mathrm{~h}$. After completion of the reaction (as monitored by LC-MS), water was added. The aqueous layer was extracted with EtOAc $(3 \times 3 \mathrm{~mL})$. The combined organic layers were concentrated in vacuo and the crude product was dissolved in 20\% TFA in $\mathrm{CH}_{2} \mathrm{Cl}_{2}$ and stirred for another $1 \mathrm{~h}$ at room temperature. After completion of the reaction (as monitored by LC-MS), the reaction mixture was concentrated in vacuo and the crude product was purified by HPLC using water: $\mathrm{ACN}$ ( $0.1 \%$ formic acid) solvent gradient to afford thalidomide amine as white solid in 45.3 $\mathrm{mg}(46 \%$ yield $)$.

ESI-MS (m/z): calculated for $\mathrm{C}_{23} \mathrm{H}_{32} \mathrm{~N}_{3} \mathrm{O}_{9}[\mathrm{M}+\mathrm{H}]+:$ : 494.21; found: $[\mathrm{M}+\mathrm{H}]+: 494.54$.

2-(((R)-3-(4-amino-3-(4-phenoxyphenyl)-1H-pyrazolo[3,4-d]pyrimidin-1-yl)piperidin-1yl)methyl)-N-(14-((2-(2,6-dioxopiperidin-3-yl)-1,3-dioxoisoindolin-4-yl)amino)-3,6,9,12tetraoxatetradecyl)acrylamide (1n)
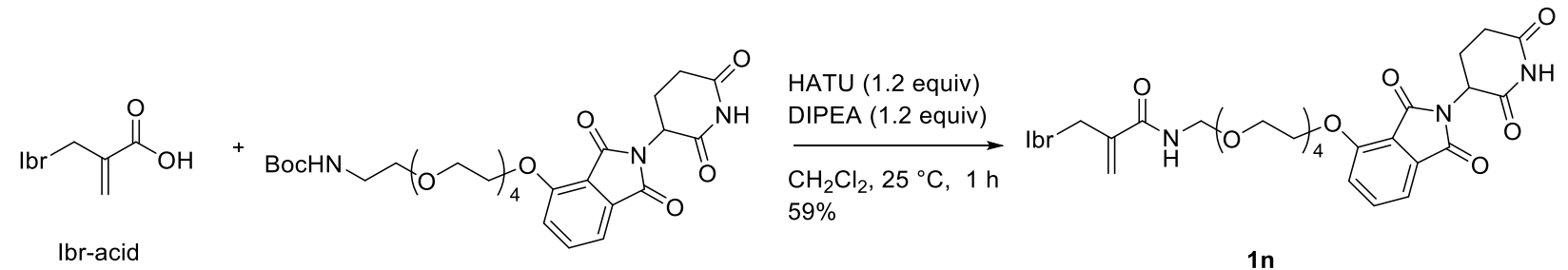

To a stirred solution of carboxylic acid $(23.5 \mathrm{mg}, 0.05 \mathrm{mmol})$ in $\mathrm{CH}_{2} \mathrm{Cl}_{2}(1 \mathrm{~mL})$, HATU ( $23 \mathrm{mg}, 0.06$ mmol), DIPEA (10.4 $\mu \mathrm{L}, 0.06 \mathrm{mmol})$ and amine pre-1n $(24.5 \mathrm{mg}, 0.05 \mathrm{mmol})$ were added at $25^{\circ} \mathrm{C}$. The reaction mixture was stirred at room temperature for $1 \mathrm{~h}$. After completion of the reaction (as monitored by LC-MS), the reaction mixture was quenched with $\mathrm{H}_{2} \mathrm{O}(2 \mathrm{~mL})$ at $0{ }^{\circ} \mathrm{C}$. The aqueous layer was extracted with $\mathrm{CH}_{2} \mathrm{Cl}_{2}(3 \times 4 \mathrm{~mL})$ evaporated under vacuo. The crude product was purified by preparative HPLC using water:ACN $(0.1 \%$ TFA) solvent gradient to afford methacrylamide (1n) as colorless solid in $15.1 \mathrm{mg}$ (yield $=59 \%$ ).

${ }^{1}$ H NMR (500 MHz, CD ${ }_{3} \mathrm{OD}$ ): $\delta 1.97$ (d, $\left.J=15.3 \mathrm{~Hz}, 1 \mathrm{H}\right), 2.06-2.15$ (m, 2H), 2.23 (br. s., $2 \mathrm{H}$ ), 2.64-2.77 (m, 2H), 2.80-2.90 (m, 1H), 3.16 (br. s., 1H), 3.39 (br. s., 2H), 3.44-3.66 (m, 15 H), 3.673.82 (m, 4H), 3.89 (br. s., 2H), 4.04 (br. s., 2H), 4.16 (d, $J=12.9$ Hz, 1H), 4.35 (br. s., 2H), 5.08 (dd, 
$J=12.7,5.4 \mathrm{~Hz}, 1 \mathrm{H}$ ), 5.49 (br. s., $1 \mathrm{H}), 6.03$ (s, 1H), 6.27 (s, 1H), 7.12 (d, $J=8.0 \mathrm{~Hz}, 2 \mathrm{H}), 7.18$ (d, $J$ $=8.4 \mathrm{~Hz}, 2 \mathrm{H}), 7.21(\mathrm{t}, J=7.4 \mathrm{~Hz}, 1 \mathrm{H}), 7.39-7.52(\mathrm{~m}, 4 \mathrm{H}), 7.75(\mathrm{t}, J=7.9 \mathrm{~Hz}, 1 \mathrm{H}), 7.91$ (br. s., $2 \mathrm{H})$, 8.45 (br. s., $1 \mathrm{H}$ ); ${ }^{13} \mathbf{C}$ NMR (126 MHz, $\mathrm{CD}_{3} \mathrm{OD}$ ): $\delta$ 18.5, 22.2, 26.7, 30.8, 39.2, 42.5, 49.0, 50.4, 51.7, 54.0, 60.0, 68.8, 69.0, 69.1, 69.8, 70.1, 70.1, 70.5, 97.1, 115.3, 116.8, 118.5, 119.4, 119.5, 124.0, 125.4, 128.0, 129.8, 130.5, 132.0, 133.7, 136.6, 147.1, 149.6, 152.2, 156.3, 159.3, 160.6, 165.9, 167.1, 167.5, 170.1, 173.1. HR-MS (m/z): Calculated for $\mathrm{C}_{49} \mathrm{H}_{56} \mathrm{~N}_{9} \mathrm{O}_{11}[\mathrm{M}+\mathrm{H}]^{+}$: 946.4099; Found $[\mathrm{M}+\mathrm{H}]^{+}$: 946.4092.

\section{3-(2-(2-aminoethoxy)ethoxy)-N-(2-(2,6-dioxopiperidin-3-yl)-1-oxoisoindolin-4- yl)propanamide (pre-10):}
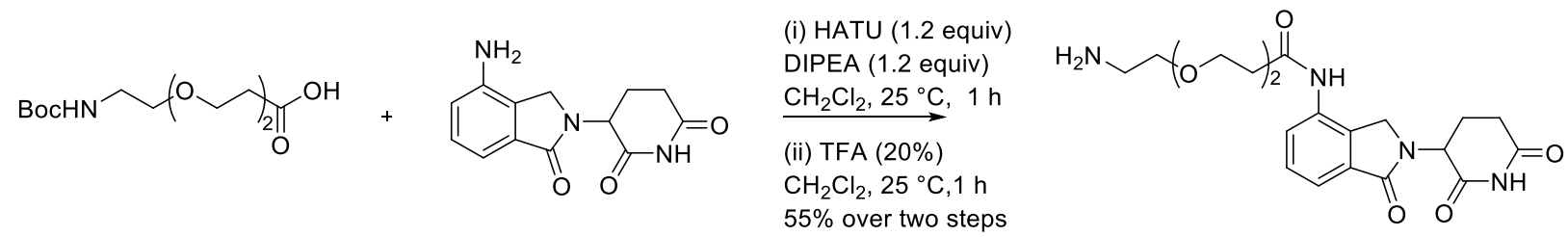

pre-10

To a stirred solution of carboxylic acid (27.7 mg, $0.1 \mathrm{mmol})$ in $\mathrm{CH}_{2} \mathrm{Cl}_{2}(1 \mathrm{~mL})$, HATU (46 mg, 0.12 mmol), DIPEA ( $20.9 \mu \mathrm{L}, 0.12 \mathrm{mmol})$ and lenalidomide $(26 \mathrm{mg}, 0.1 \mathrm{mmol})$ were added at $25^{\circ} \mathrm{C}$. The reaction mixture was stirred at room temperature for $1 \mathrm{~h}$. After completion of the reaction (as monitored by LC-MS), water was added and the aqueous layer was extracted with $\mathrm{CH}_{2} \mathrm{Cl}_{2}(3 \times 3$ $\mathrm{mL}$ ). The combined organic layer was concentrated in vacuo and the crude product was dissolved $20 \%$ TFA in DCM and allowed to stir at room temperature for $1 \mathrm{~h}$. After completion, the reaction mixture was evaporated under vacuo and the crude product was purified by HPLC using water:ACN ( $0.1 \%$ formic acid) solvent gradient to afford thalidomide amine (pre-1o) as white solid in $23 \mathrm{mg}$ (55\% yield).

ESI-MS (m/z): calculated for $\mathrm{C}_{19} \mathrm{H}_{25} \mathrm{~N}_{4} \mathrm{O}_{6}[\mathrm{M}+\mathrm{H}]+:$ : 405.13; found: $[\mathrm{M}+\mathrm{H}]+: 405.65$.

3-(2-(2-((R)-3-(4-amino-3-(4-phenoxyphenyl)-1H-pyrazolo[3,4-d]pyrimidin-1-yl)piperidin-1yl)ethoxy)ethoxy)-N-(2-(2,6-dioxopiperidin-3-yl)-1-oxoisoindolin-4-yl)propanamide (10) 


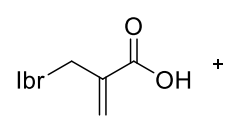

Ibr-acid

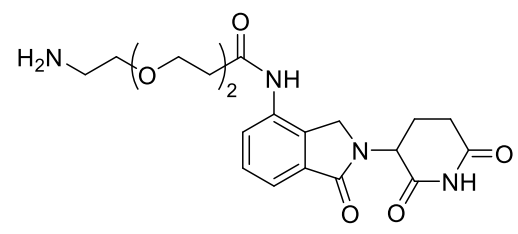

To a stirred solution of carboxylic acid ( $23.5 \mathrm{mg}, 0.05 \mathrm{mmol})$ in $\mathrm{CH}_{2} \mathrm{Cl}_{2}(1 \mathrm{~mL})$, HATU ( $23 \mathrm{mg}, 0.06$ mmol), DIPEA (10.4 $\mu \mathrm{L}, 0.06 \mathrm{mmol})$ and amine pre-1o $(21 \mathrm{mg}, 0.1 \mathrm{mmol})$ were added at $25^{\circ} \mathrm{C}$. The reaction mixture was stirred at room temperature for $1 \mathrm{~h}$. After completion of the reaction (as monitored by LC-MS), water was added and the aqueous layer was extracted with $\mathrm{CH}_{2} \mathrm{Cl}_{2}(3 \times 3$ $\mathrm{mL}$ ). The organic layer was concentrated in vacuo and the crude product was purified by HPLC using water: $\mathrm{ACN}(0.1 \%$ formic acid) solvent gradient to afford white solid $1 \mathrm{o}$ in $26.9 \mathrm{mg}$ (62\% yield).

${ }^{1}$ H NMR (400 MHz, CD ${ }_{3} \mathrm{OD} \delta 1.39$ (s, 2H), 2.02 (br. s., 2H), 2.17-2.38 (m, 4H), 2.53 (qd, $J=13.2$, $4.7 \mathrm{~Hz}, 1 \mathrm{H}), 2.74(\mathrm{t}, J=5.1 \mathrm{~Hz}, 2 \mathrm{H}), 2.81-2.92(\mathrm{~m}, 1 \mathrm{H}), 2.93-3.04(\mathrm{~m}, 1 \mathrm{H}), 3.13-3.26(\mathrm{~m}, 1 \mathrm{H}), 3.53-$ 3.63 (m, 3H), 3.63-3.77 (m, 6H), 3.81 (br. s., 1H), 3.89 (t, $J=5.7 \mathrm{~Hz}, 2 \mathrm{H}), 4.01$ (d, $J=12.8 \mathrm{~Hz}, 1 \mathrm{H})$, 4.09-4.21 (m, 2H), 4.55 (s, 2H), 5.24 (dd, $J=13.3,5.2 \mathrm{~Hz}, 1 \mathrm{H}), 5.48$ (br. s., $1 \mathrm{H}), 5.98$ (d, $J=5.9 \mathrm{~Hz}$, 1H), 6.22-6.28 (m, 1H), 7.20 (d, $J=7.7 \mathrm{~Hz}, 2 \mathrm{H}), 7.23-7.33(\mathrm{~m}, 3 \mathrm{H}), 7.47-7.61(\mathrm{~m}, 3 \mathrm{H}), 7.69$ (d, $J=$ $5.9 \mathrm{~Hz}, 1 \mathrm{H}), 7.78(\mathrm{dd}, J=7.5,4.8 \mathrm{~Hz}, 1 \mathrm{H}), 7.88-8.00(\mathrm{~m}, 2 \mathrm{H}), 8.46(\mathrm{~s}, 1 \mathrm{H}) ;{ }^{13} \mathbf{C} \mathbf{N M R}(101 \mathrm{MHz}$, CD3OD $\delta 18.5,22.8,26.9,29.4,30.9,36.4,39.1,50.6,51.6,52.2,54.0,59.7,66.6,68.9,69.8,69.9$, 97.5, 118.5, 119.3, 120.1, 123.9, 126.4, 127.9, 128.7, 129.8, 130.4, 132.5, 133.2, 135.0, 156.4, 159.0, 167.3, 169.6, 170.9, 173.2; HR-MS (m/z): Calculated for $\mathrm{C}_{42} \mathrm{H}_{46} \mathrm{~N}_{9} \mathrm{O}_{7}[\mathrm{M}+\mathrm{H}]^{+}:$788.3520; Found $[\mathrm{M}+\mathrm{H}]^{+}: 788.3524$.

\section{1-amino-N-(2-(2,6-dioxopiperidin-3-yl)-1-oxoisoindolin-4-yl)-3,6,9,12-tetraoxapentadecan-} 15-amide (pre-1p)

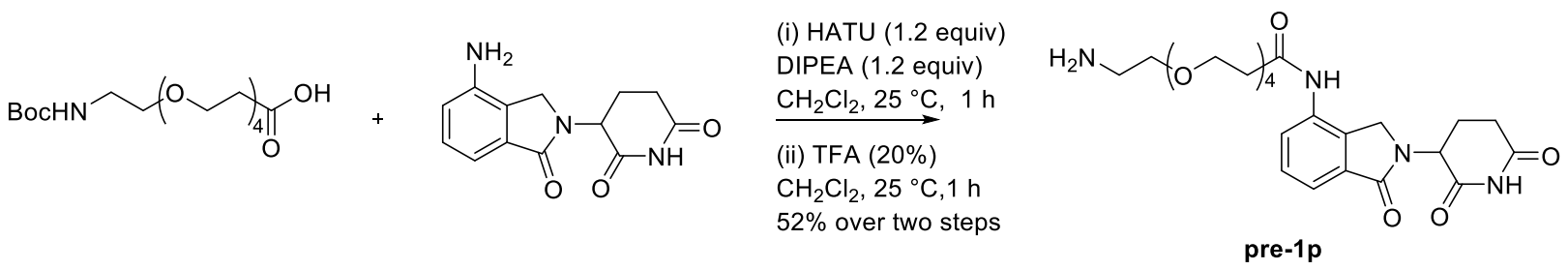

To a stirred solution of carboxylic acid ( $36.5 \mathrm{mg}, 0.1 \mathrm{mmol})$ in $\mathrm{CH}_{2} \mathrm{Cl}_{2}(1 \mathrm{~mL})$, HATU (46 mg, 0.12 mmol), DIPEA ( $21 \mu \mathrm{L}, 0.12 \mathrm{mmol})$ and lenalidomide $(26 \mathrm{mg}, 0.1 \mathrm{mmol})$ were added at $25^{\circ} \mathrm{C}$. The reaction mixture was stirred at room temperature for $1 \mathrm{~h}$. After completion of the reaction (as monitored by LC-MS), water was added. The aqueous layer was extracted with $\mathrm{CH}_{2} \mathrm{Cl}_{2}(3 \times 3 \mathrm{~mL})$. 
The organic layer was concentrated in vacuo and the crude product was dissolved in $20 \%$ TFA in DCM and allowed to stir at $25^{\circ} \mathrm{C}$ for $2 \mathrm{~h}$. The reaction mixture was concentrated and purified HPLC using water: $\mathrm{ACN}$ ( $0.1 \%$ formic acid) solvent gradient to afford pre-1p white solid in $26.3 \mathrm{mg}$ (52\% yield).

ESI-MS (m/z): calculated for $\mathrm{C}_{24} \mathrm{H}_{35} \mathrm{~N}_{4} \mathrm{O}_{8}[\mathrm{M}+\mathrm{H}]+$ : 507.24; found: $[\mathrm{M}+\mathrm{H}]+: 507.34$.

\section{1-(2-(((R)-3-(4-amino-3-(4-phenoxyphenyl)-1H-pyrazolo[3,4-d]pyrimidin-1-yl)piperidin-1-}

yl)methyl)acrylamido)-N-(2-(2,6-dioxopiperidin-3-yl)-1-oxoisoindolin-4-yl)-3,6,9,12-

tetraoxapentadecan-15-amide (1p)

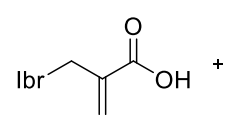

Ibr-acid

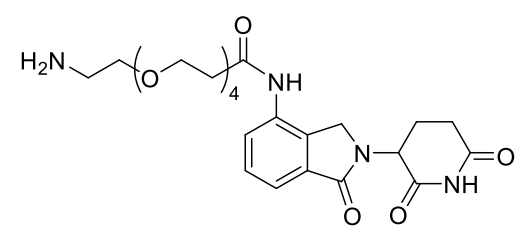

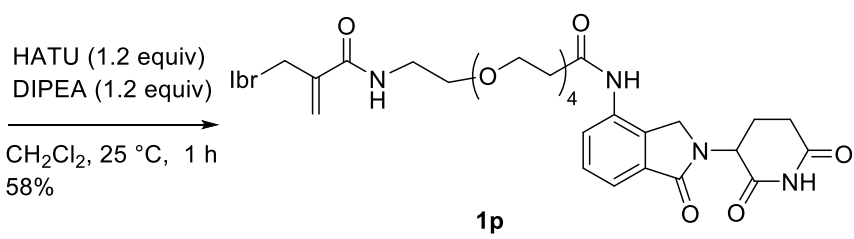

$1 p$

To a stirred solution of carboxylic acid $(23.5 \mathrm{mg}, 0.05 \mathrm{mmol})$ in $\mathrm{CH}_{2} \mathrm{Cl}_{2}(1 \mathrm{~mL})$, HATU (23 mg, 0.06 mmol), DIPEA $(10.4 \mu \mathrm{L}, 0.06 \mathrm{mmol})$ and pre $1 p$ amine $(25 \mathrm{mg}, 0.1 \mathrm{mmol})$ were added at $25^{\circ} \mathrm{C}$. The reaction mixture was stirred at room temperature for $1 \mathrm{~h}$. After completion of the reaction (as monitored by LC-MS), water was added. the aqueous layer was extracted with $\mathrm{CH}_{2} \mathrm{Cl}_{2}(3 \times 3 \mathrm{~mL})$. The organic layer was concentrated in vacuo and the crude product was purified by HPLC using water: $\mathrm{ACN}$ ( $0.1 \%$ formic acid) solvent gradient to afford white solid 1p in $27.84 \mathrm{mg}$ (58\% yield).

${ }^{1} \mathbf{H}$ NMR (500 MHz, CD ${ }_{3} \mathrm{OD} \delta$ 0.83-0.94 (m, 1H), 1.27-1.39 (m, 7H), 1.63 (br. s., 1H), 1.88-2.00 (m, 1H), 2.05 (br. s., 1H), 2.20 (br. s., 4H), 2.28 (br. s., 1H), 2.40-2.52 (m, 1H), 2.68 (br. s., 2H), 2.752.84 (m, 1H), 2.89 (d, J=14.3 Hz, 1H), 3.13 (br. s., 1H), 3.18 (br. s., 1H), 3.50 (s, 6H), 3.47 (s, 5 H), 3.57 (br. s., 4H), 3.63 (br. s., 7H), 3.75 (br. s., 2H), 3.83 (br. s., 3H), 3.99 (br. s., 1H), 4.06 (br. s., 1H), 4.13 (d, $J=11.4 \mathrm{~Hz}, 1 \mathrm{H}), 4.49$ (br. s., 2H), 5.12-5.24 (m, 1H), 5.42 (br. s., 1H), 6.00 (br. s., 1H), 6.24 (br. s., 1H), 7.13 (br. s., 2H), 7.15-7.26 (m, 4H), 7.44 (br. s., 2H), 7.50 (br. s., 1H), 7.62 (br. s., 1H), 7.73 (br. s., 2H), 7.88 (br. s., 2H), 8.39 (br. s., 1 H); ${ }^{13}$ C NMR (125 MHz, CD3OD $\delta$ 14.6, 20.1, 23.9, 24.3, 28.4, 30.9, 32.5, 38.1, 40.7, 52.1, 53.8, 55.6, 61.4, 68.2, 70.4, 71.3, 71.5, 71.6, 71.6, 120.0, 120.9, 121.6, 125.5, 127.9, 129.5, 130.2, 131.3, 132.0, 134.1, 134.7, 142.0, 143.0, 154.5, 157.3, 160.6, 168.9, 171.2, 174.8; HR-MS (m/z): Calculated for $\mathrm{C}_{49} \mathrm{H}_{57} \mathrm{~N}_{10} \mathrm{O}_{10}[\mathrm{M}+\mathrm{H}]^{+}$: 945.4259; Found $[\mathrm{M}+\mathrm{H}]^{+}$: 945.4256. 


\section{(R)-1-amino-N-(3-(3-(3-(4-amino-3-(4-phenoxyphenyl)-1H-pyrazolo[3,4-d]pyrimidin-1-}

yl)piperidin-1-yl)-3-oxopropyl)-14-(11-oxidaneyl)-313,6,9,12-tetraoxatetradecyl)-3,6,9,12,15pentaoxaoctadecan-18-amide (1r):

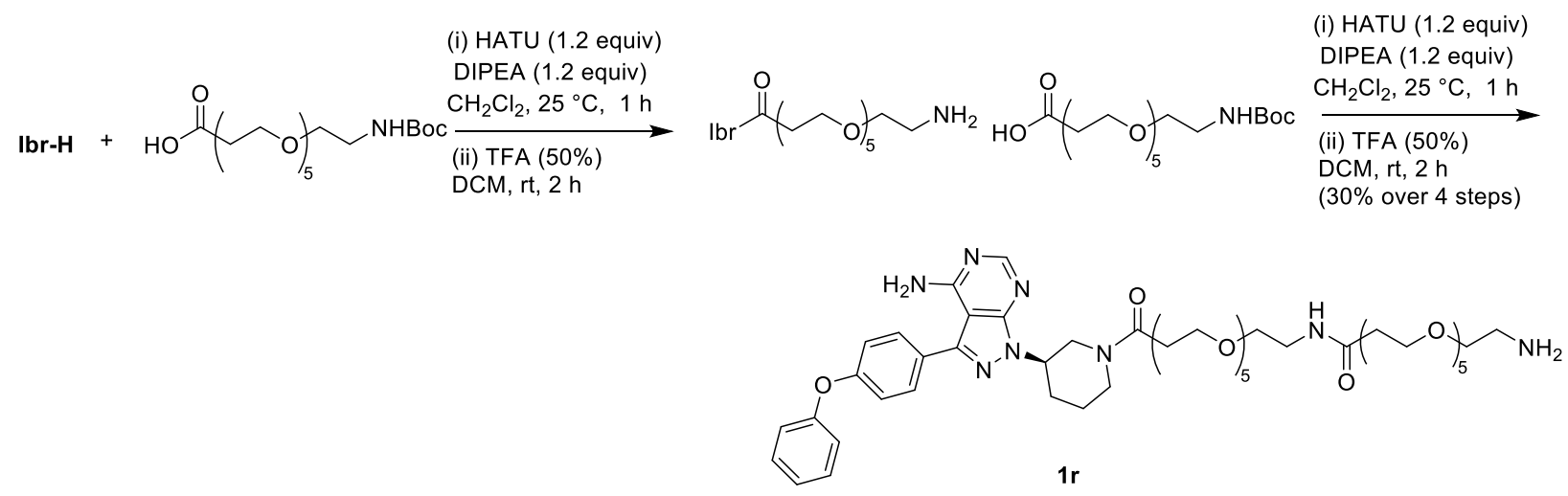

To a stirred solution of carboxylic acid (40.9 mg, $0.1 \mathrm{mmol}$ ) in $\mathrm{CH}_{2} \mathrm{Cl}_{2}(5 \mathrm{~mL})$, HATU (45.6 mg, 0.12 mmol), DIPEA $(20.9 \mu \mathrm{L}, 0.12 \mathrm{mmol})$ and ibr-H $(38.7 \mathrm{mg}, 0.1 \mathrm{mmol})$ were added at $25{ }^{\circ} \mathrm{C}$. The reaction mixture was stirred at room temperature for $1 \mathrm{~h}$. After completion of the reaction (as monitored by LC-MS), $3 \mathrm{~mL}$ water was added. The aqueous layer was extracted with $\mathrm{CH}_{2} \mathrm{Cl}_{2}(3 \times 5$ $\mathrm{mL}$ ). The combined organic layers were concentrated in vacuo and the crude product was dissolved in $20 \%$ TFA in DCM and allowed to stir at $25^{\circ} \mathrm{C}$ for $2 \mathrm{~h}$. The reaction mixture was concentrated to give the crude amine which was used as such for the next reaction.

To a stirred solution of carboxylic acid ( $40.9 \mathrm{mg}, 0.1 \mathrm{mmol}$ ) in $\mathrm{CH}_{2} \mathrm{Cl}_{2}(5 \mathrm{~mL})$, HATU (45.6 mg, 0.12 mmol), DIPEA ( $20.9 \mu \mathrm{L}, 0.12 \mathrm{mmol})$ and crude amine $(0.1 \mathrm{mmol})$ (obtained in previous step) were added at $25^{\circ} \mathrm{C}$. The reaction mixture was stirred at room temperature for $1 \mathrm{~h}$. After completion of the reaction (as monitored by LC-MS), $3 \mathrm{~mL}$ water was added. The aqueous layer was extracted with $\mathrm{CH}_{2} \mathrm{Cl}_{2}(3 \times 5 \mathrm{~mL})$. The combined organic layers were concentrated in vacuo and the crude product was dissolved in $20 \%$ TFA in DCM and allowed to stir at $25{ }^{\circ} \mathrm{C}$ for $2 \mathrm{~h}$. The reaction mixture was concentrated and purified HPLC using water: $\mathrm{ACN}(0.1 \%$ formic acid $)$ solvent gradient to afford white solid $\mathbf{1 r}$ in $29 \mathrm{mg}$ ( $30 \%$ yield).

ESI-MS (m/z): calculated for $\mathrm{C}_{48} \mathrm{H}_{73} \mathrm{~N}_{8} \mathrm{O}_{13}[\mathrm{M}+\mathrm{H}]+:$ 969.53; found: [M+H]+:969.89. 


\section{2-((4-(((6-amino-5-(4-phenoxyphenyl)pyrimidin-4-yl)amino)methyl)piperidin-1-yl)methyl)-N-}

\section{(but-3-yn-1-yl)acrylamide (2a)}
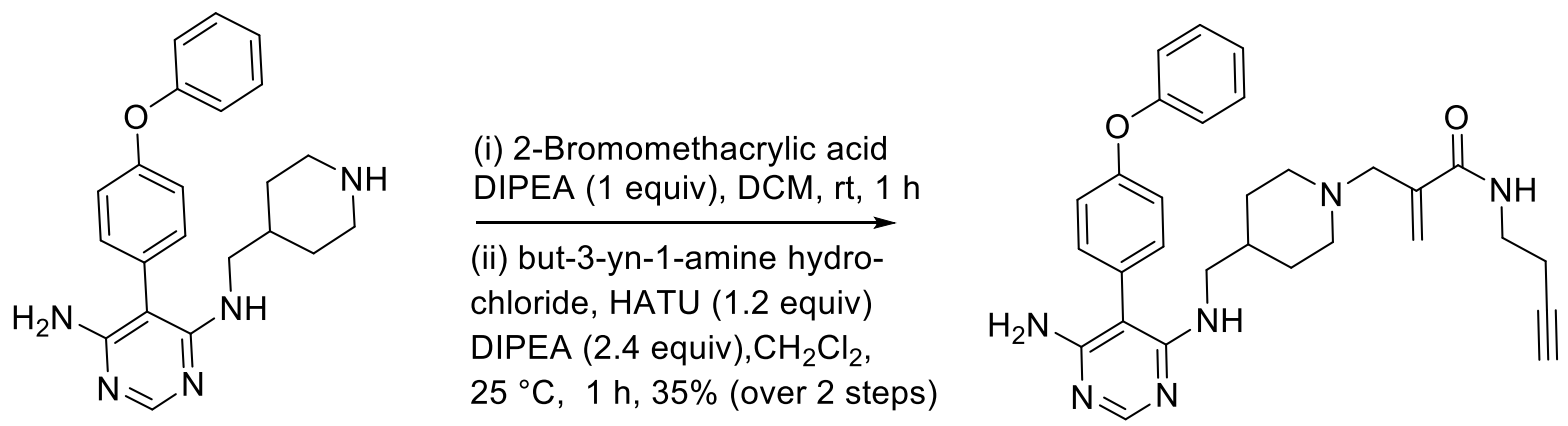

$2 a$

To a stirred solution of evoburtinib amine $(37.5 \mathrm{mg}, 0.1 \mathrm{mmol})$ in anhydrous DCM (1 mL), DIPEA $(17.8 \mu \mathrm{L}, 0.1 \mathrm{mmol})$ and 2-(bromomethyl)acrylic acid $(16.1 \mathrm{mg}, 0.1 \mathrm{mmol})$ were added at $25^{\circ} \mathrm{C}$. The reaction mixture was stirred at room temperature for $1 \mathrm{~h}$. After completion of the reaction (as monitored by LC-MS), $1 \mathrm{~mL}$ of $\mathrm{H}_{2} \mathrm{O}$ was added and the aqueous layer was extracted with $\mathrm{CH}_{2} \mathrm{Cl}_{2}(3$ $\times 2 \mathrm{~mL}$ ). The combined organic layers was concentrated in vacuo and the crude product was used for the next reaction without further purification.

To a solution of crude evabrutinib carboxylic acid in $\mathrm{CH}_{2} \mathrm{Cl}_{2}(1 \mathrm{~mL})$, HATU (46 mg, $0.12 \mathrm{mmol}$ ), DIPEA (41.8 $\mu \mathrm{L}, 0.24 \mathrm{mmol})$ and but-3-yn-1-aminehydrochloride (12.6 mg, $0.12 \mathrm{mmol})$ were added at $25{ }^{\circ} \mathrm{C}$. The reaction mixture was stirred at room temperature for $1 \mathrm{~h}$. After completion of the reaction (as monitored by LC-MS), water $(2 \mathrm{~mL})$ was added and the aqueous layer was extracted with $\mathrm{CH}_{2} \mathrm{Cl}_{2}(3 \times 3 \mathrm{~mL})$. The combined organic layer was concentrated in vacuo and the crude product was purified by preparative HPLC using water:ACN $(0.1 \%$ formic acid $)$ solvent gradient to afford white solid 2a in $17.8 \mathrm{mg}(35 \%$ yield $)$.

${ }^{1}$ H NMR (500 MHz, CD $\left.3 \mathrm{OD}\right): \delta 1.44-1.56(\mathrm{~m}, 2 \mathrm{H}), 1.95(\mathrm{~d}, J=12.2 \mathrm{~Hz}, 3 \mathrm{H}), 2.33(\mathrm{t}, J=2.6 \mathrm{~Hz}$, 1H), $2.47(\mathrm{td}, J=6.9,2.6 \mathrm{~Hz}, 2 \mathrm{H}), 2.94(\mathrm{t}, J=12.3 \mathrm{~Hz}, 2 \mathrm{H}), 3.43(\mathrm{t}, J=6.9 \mathrm{~Hz}, 4 \mathrm{H}), 3.57(\mathrm{~d}, J=11.8$ $\mathrm{Hz}, 2 \mathrm{H}), 3.97$ (s, 2H), 6.01 (s, 1H), 6.25 (s, 1H), 7.14 (d, J=8.7 Hz, 2H), 7.18-7.23 (m, 3H), 7.32 (d, $J=8.7 \mathrm{~Hz}, 2 \mathrm{H}), 7.43$ (t, $J=8.0 \mathrm{~Hz}, 2 \mathrm{H}), 8.27(\mathrm{~s}, 1 \mathrm{H}) ;{ }^{13} \mathbf{C}$ NMR (126 MHz, CD $\left.{ }_{3} \mathrm{OD}\right): \delta$ 18.1, 27.0, $33.9,38.3,45.2,52.4,58.2,69.5,80.7,95.6,119.3,119.8,122.9,123.8,128.3,129.7,132.0,133.3$, 148.1, 156.4, 158.9, 167.5. HR-MS (m/z): Calculated for $\mathrm{C}_{30} \mathrm{H}_{35} \mathrm{~N}_{6} \mathrm{O}_{2}[\mathrm{M}+\mathrm{H}]^{+}:$511.2821; Found $[\mathrm{M}+\mathrm{H}]^{+}:$511.2816. 


\section{N-(but-3-yn-1-yl)-2-(((3S)-4-(6-fluoro-7-(2-fluoro-6-hydroxyphenyl)-1-(2-isopropyl-4-}

methylpyridin-3-yl)-2-oxo-1,2-dihydropyrido[2,3-d]pyrimidin-4-yl)-3-methylpiperazin-1yl)methyl)acrylamide (3a)

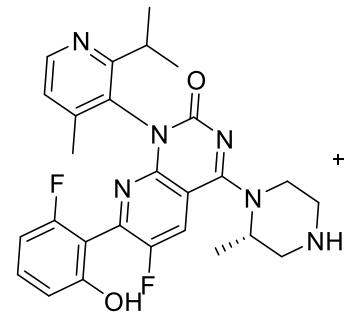

amg-510-H

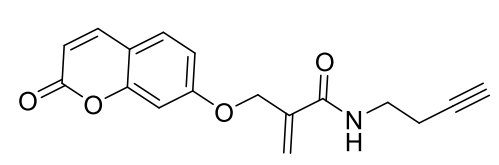

$\underset{\text { DCM, rt, } 12 \mathrm{~h}}{\stackrel{\text { DIPEA (1 equiv) }}{\longrightarrow}}$

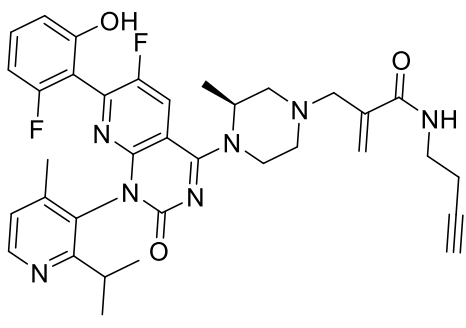

$3 a$

To a stirred solution of amg-510 amine $(2.5 \mathrm{mg}, 0.005 \mathrm{mmol})$ in anhydrous DCM $(1 \mathrm{~mL})$, DIPEA $(1.73 \mu \mathrm{L}, 0.01 \mathrm{mmol})$ and compound $3 \mathbf{a}^{2}(2.9 \mathrm{mg}, 0.01 \mathrm{mmol})$ were added at $25{ }^{\circ} \mathrm{C}$. The reaction mixture was stirred at room temperature for $12 \mathrm{~h}$. After completion of the reaction (as monitored by LC-MS), $\mathrm{CH}_{2} \mathrm{Cl}_{2}$ was concentrated in vacuo to obtain the crude carboxylic acid. The crude product was purified by preparative HPLC using water:ACN $(0.1 \%$ formic acid) solvent gradient to afford white solid 3a in $1 \mathrm{mg}$ (31.0\% yield).

${ }^{1} \mathbf{H}$ NMR (400 MHz, $\left.\mathrm{CD}_{3} \mathrm{COCD}_{3}\right) \delta$ 1.09-1.18 (m, 3H), $1.27(\mathrm{~d}, J=6.6 \mathrm{~Hz}, 3 \mathrm{H}), 1.64(\mathrm{dd}, J=6.4$, $4.2 \mathrm{~Hz}, 3 \mathrm{H}), 2.52-2.61$ (m, 3H), 2.93-2.98 (m, 1H), 3.27 (d, J=9.7 Hz, 1H), 3.49-3.67 (m, 4H), 3.88 $(\mathrm{d}, J=12.8 \mathrm{~Hz}, 1 \mathrm{H}), 3.95-4.05(\mathrm{~m}, 1 \mathrm{H}), 4.08-4.23(\mathrm{~m}, 1 \mathrm{H}), 4.37$ (dd, $J=13.1,3.9 \mathrm{~Hz}, 1 \mathrm{H}), 4.54-4.68$ $(\mathrm{m}, 2 \mathrm{H}), 6.09(\mathrm{~s}, 1 \mathrm{H}), 6.37(\mathrm{~s}, 1 \mathrm{H}), 6.78(\mathrm{t}, J=9.0 \mathrm{~Hz}, 1 \mathrm{H}), 6.85(\mathrm{~d}, J=8.4 \mathrm{~Hz}, 1 \mathrm{H}), 7.34-7.45(\mathrm{~m}$, $2 \mathrm{H}), 8.50(\mathrm{~d}, J=9.0 \mathrm{~Hz}, 1 \mathrm{H}), 8.62(\mathrm{~d}, J=5.1 \mathrm{~Hz}, 1 \mathrm{H}) .{ }^{13} \mathbf{C}$ NMR $\left(101 \mathrm{MHz}, \mathrm{CD}_{3} \mathrm{COCD}_{3}\right) \delta 14.5$, 18.0, 19.6, 22.0, 22.3, 31.0, 39.2, 47.7, 53.3, 55.0, 58.3, 71.4, 82.7, 106.7, 107.2, 107.4, 113.0, 124.1, 124.3, 124.8, 128.2, 132.4, 133.0, 133.2, 148.5, 148.7, 150.8, 154.8, 158.0, 162.9, 164.3, 164.8, 164.9, 167.6; HR-MS (m/z): Calculated for $\mathrm{C}_{35} \mathrm{H}_{38} \mathrm{~F}_{2} \mathrm{~N}_{7} \mathrm{O}_{3}[\mathrm{M}+\mathrm{H}]^{+}:$642.3004; Found $[\mathrm{M}+\mathrm{H}]^{+}: 642.3009$.

\section{2-(ethoxycarbonyl)allyl 3,4,5-trimethoxybenzoate (4a)}<smiles>COc1cc(C(=O)O)cc(OC)c1OC</smiles><smiles>C=C(CBr)C(=O)OCC</smiles>

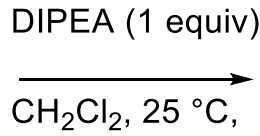
$1 \mathrm{~h}, 66 \%$<smiles>C=C(COC(=O)c1cc(OC)c(OC)c(OC)c1)C(=O)OCC</smiles> 
To a stirred solution of 3,4,5 trimethoxy benzoic acid $(21.7 \mathrm{mg}, 0.1 \mathrm{mmol})$ in anhydrous DCM (1 $\mathrm{mL})$, DIPEA $(17 \mu \mathrm{L}, 0.1 \mathrm{mmol})$ and ethyl bromo methacrylate $(14.6 \mu \mathrm{L}, 0.1 \mathrm{mmol})$ were added at 25

${ }^{\circ} \mathrm{C}$. The reaction mixture was stirred at room temperature for $1 \mathrm{~h}$. After completion of the reaction (as monitored by LC-MS), $\mathrm{CH}_{2} \mathrm{Cl}_{2}$ was concentrated in vacuo to obtain the crude carboxylic acid. The crude product was purified by HPLC using water:ACN $(0.1 \%$ formic acid $)$ solvent gradient to afford white solid 4a in $10.7 \mathrm{mg}(31.0 \%$ yield $)$.

${ }^{1} \mathbf{H}$ NMR $\left(500 \mathrm{MHz}, \mathrm{CDCl}_{3}\right) \delta 1.31(\mathrm{t}, J=7.1 \mathrm{~Hz}, 3 \mathrm{H}), 3.90(\mathrm{~s}, 10 \mathrm{H}), 4.26(\mathrm{q}, J=7.2 \mathrm{~Hz}, 2 \mathrm{H}), 5.06$ (s, 2H), 5.89 (s, 1H), 6.41 (s, 1H), 7.31 (s, $2 \mathrm{H}) ;{ }^{13} \mathbf{C} \mathbf{N M R}\left(126 \mathrm{MHz}, \mathrm{CDCl}_{3}\right) \delta$ 14.1, 56.2, 60.9, 61.0, 62.9, 106.9, 124.8, 127.1, 135.6, 142.4, 152.9, 165.2, 165.5; HR-MS (m/z): Calculated for $\mathrm{C}_{16} \mathrm{H}_{20} \mathrm{NaO}_{7}[\mathrm{M}+\mathrm{Na}]^{+}: 347.1107$; Found $[\mathrm{M}+\mathrm{Na}]^{+}: 347.1103$.

References:

(1) Gabizon, R.; Shraga, A.; Gehrtz, P.; Livnah, E.; Shorer, Y.; Gurwicz, N.; Avram, L.; Unger, T.; Aharoni, H.; Albeck, S.; Brandis, A.; Shulman, Z.; Katz, B.-Z.; Herishanu, Y.; London, N. Efficient Targeted Degradation via Reversible and Irreversible Covalent PROTACs. J. Am. Chem. Soc. 2020, 142 (27), 11734-11742. https://doi.org/10.1021/jacs.9b13907.

(2) Pode, Z.; Peri-Naor, R.; Georgeson, J. M.; Ilani, T.; Kiss, V.; Unger, T.; Markus, B.; Barr, H. M.; Motiei, L.; Margulies, D. Protein Recognition by a Pattern-Generating Fluorescent Molecular Probe. Nat. Nanotechnol. 2017, 12 (12), 1161-1168.

(3) Reddi, R. N.; Resnick, E.; Rogel, A.; Rao, B. V.; Gabizon, R.; Goldenberg, K.; Gurwicz, N.; Zaidman, D.; Plotnikov, A.; Barr, H.; Shulman, Z.; London, N. Tunable Methacrylamides for Covalent Ligand Directed Release Chemistry. J. Am. Chem. Soc. 2021, 143 (13), 4979-4992. 
NMR Spectra

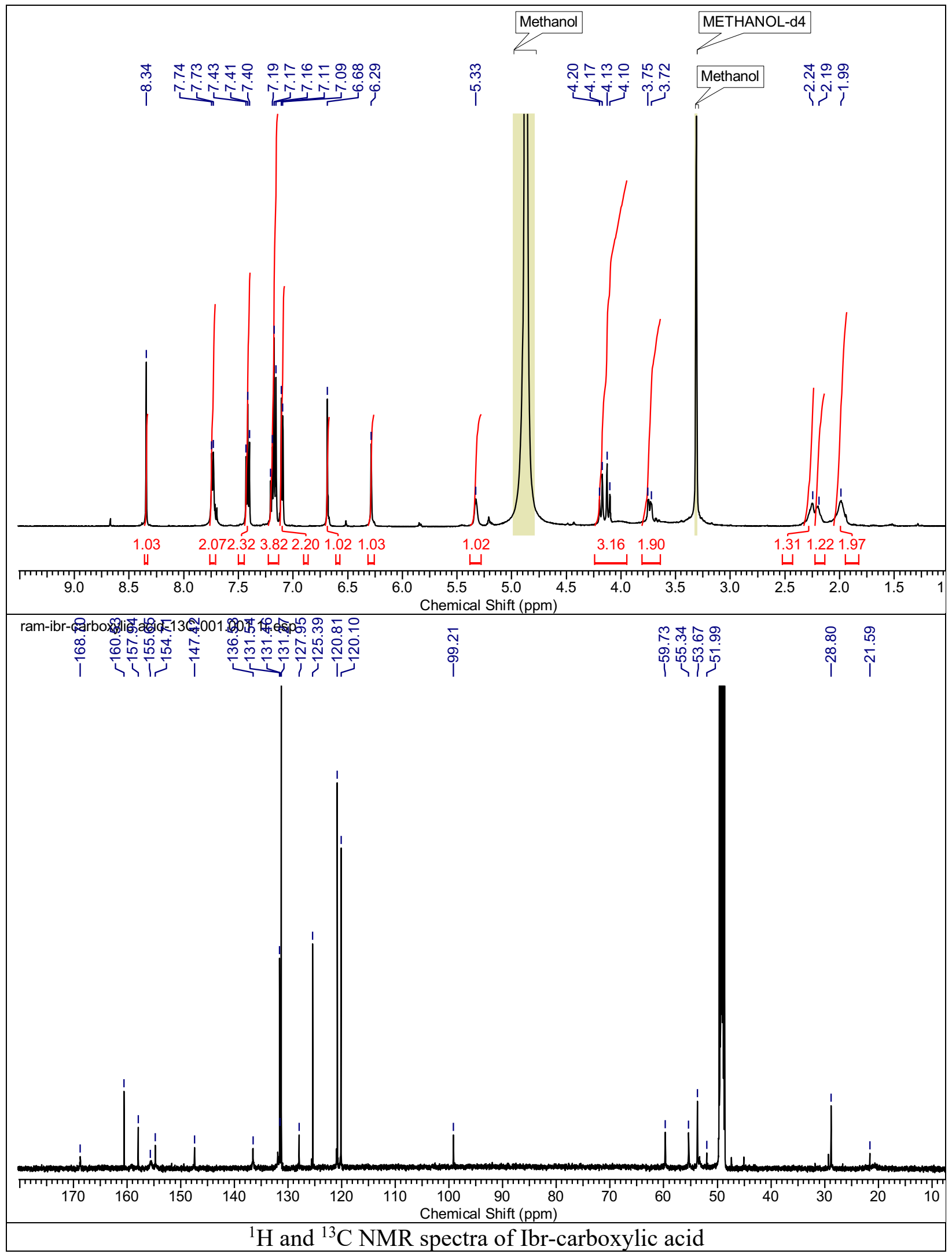




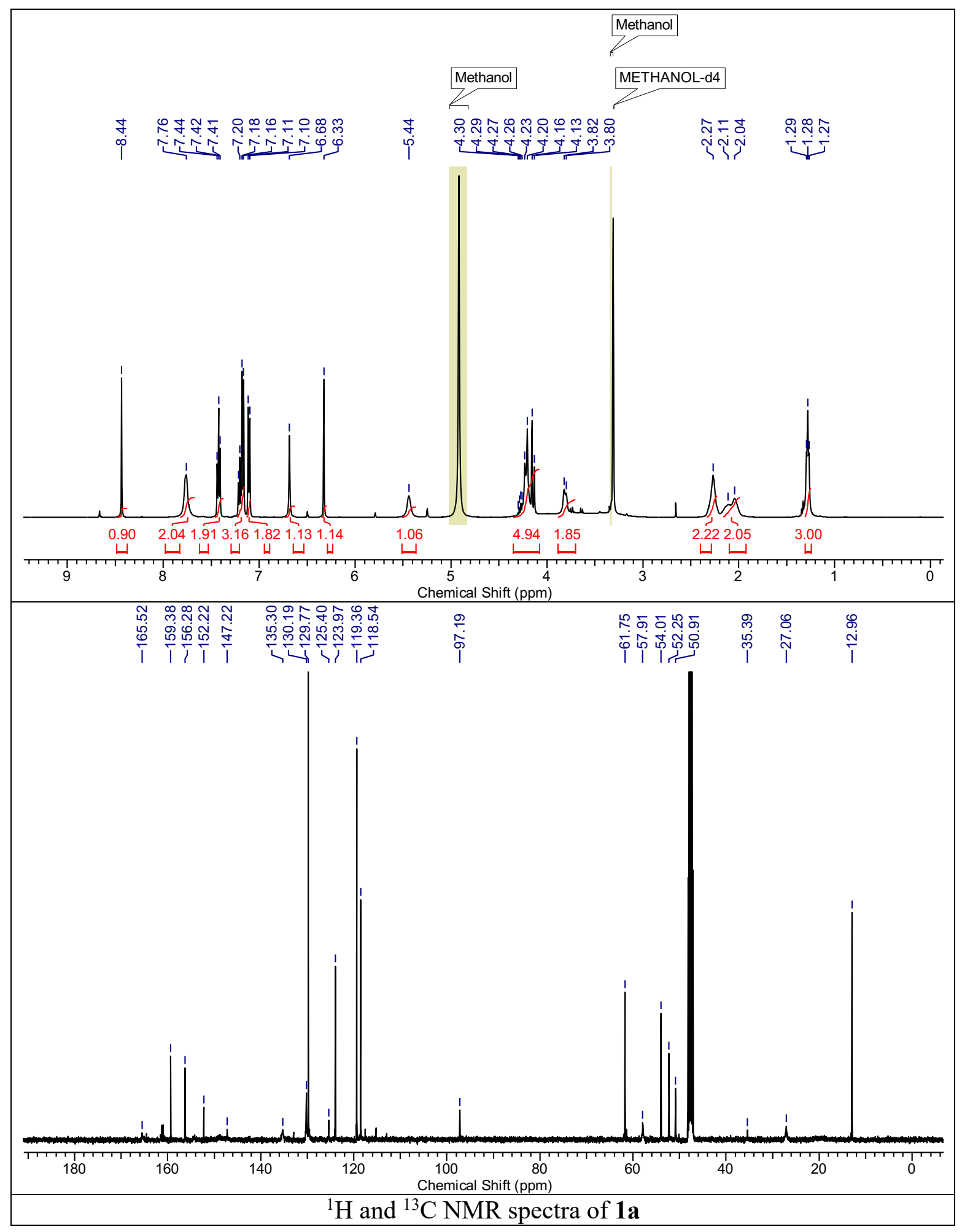




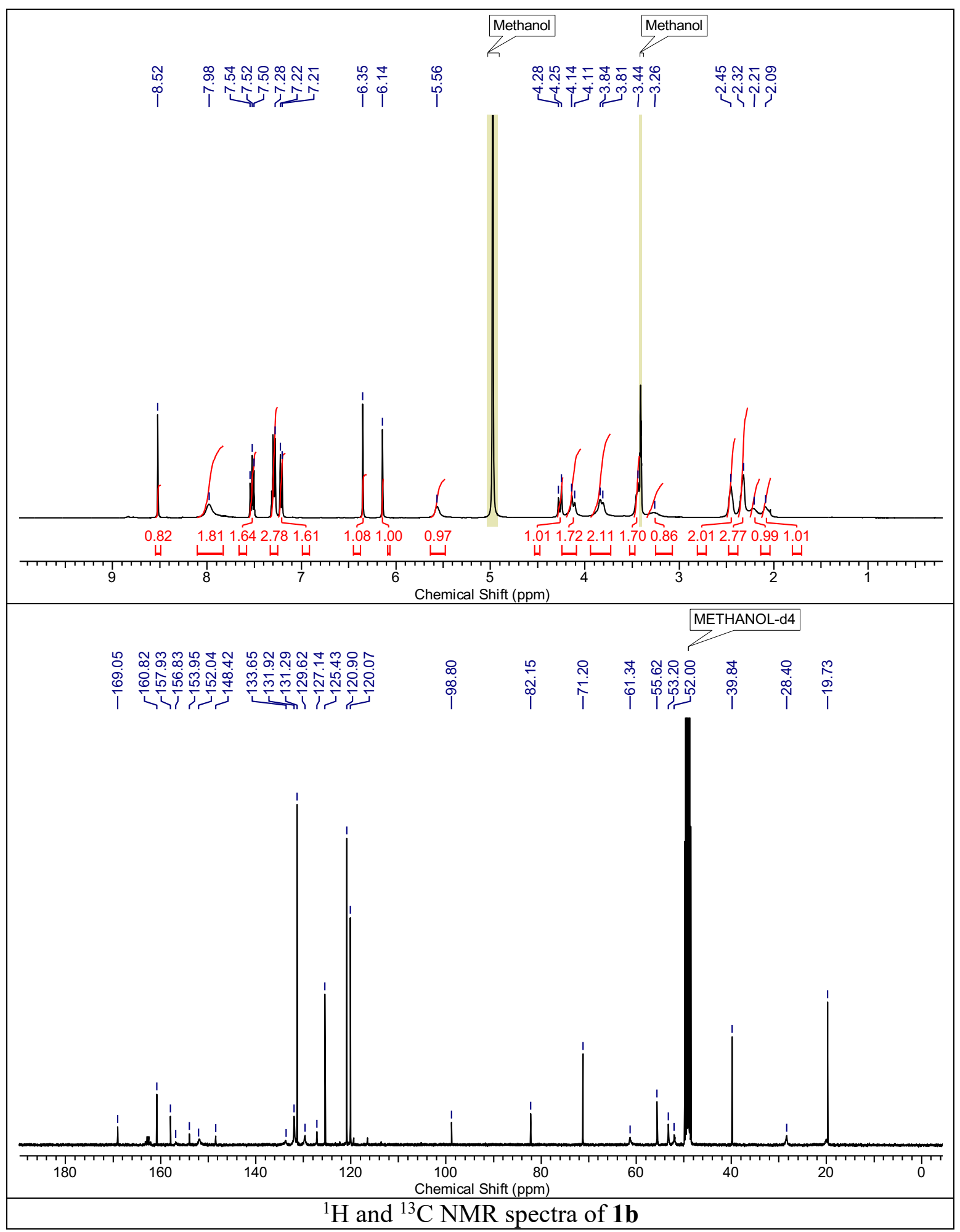




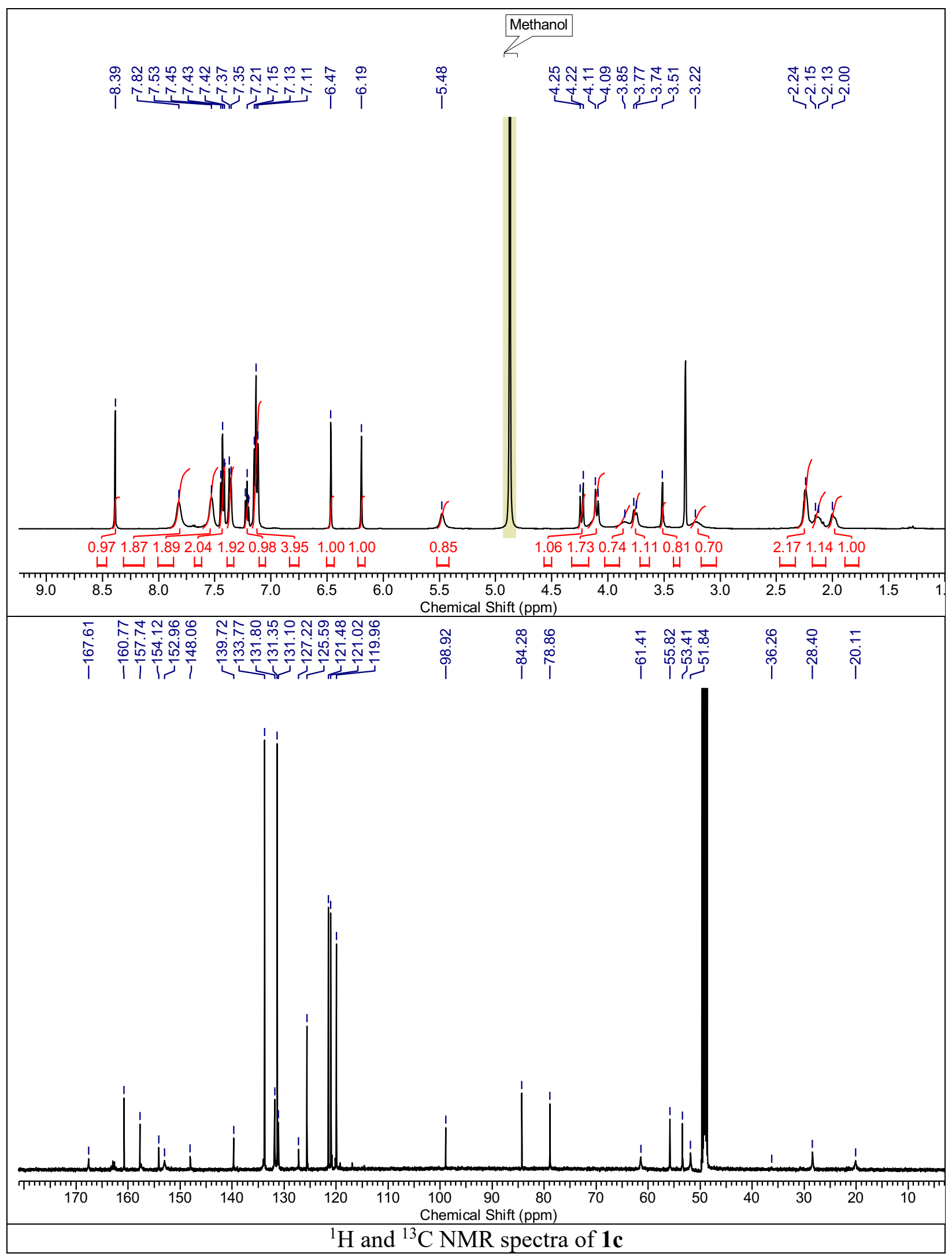




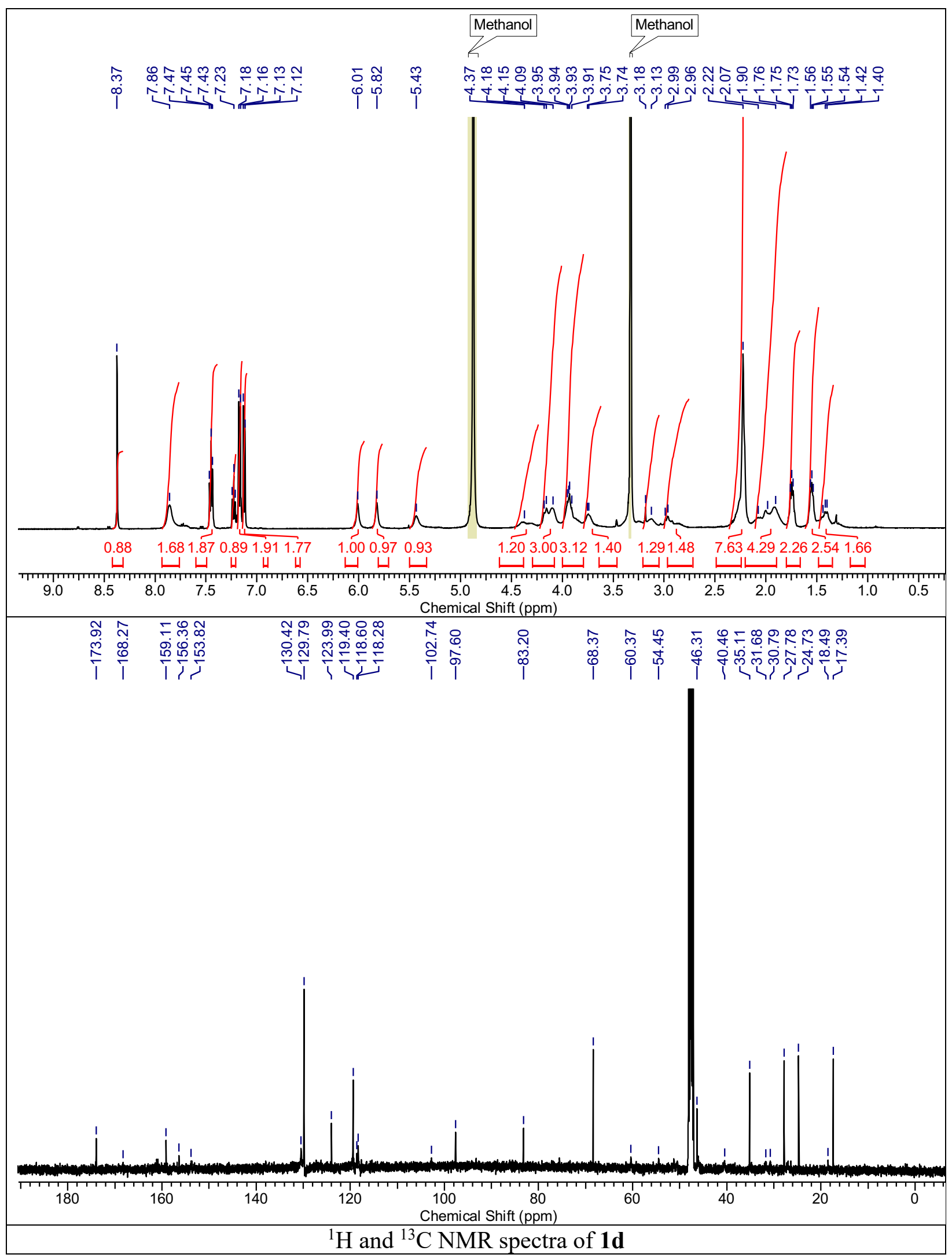




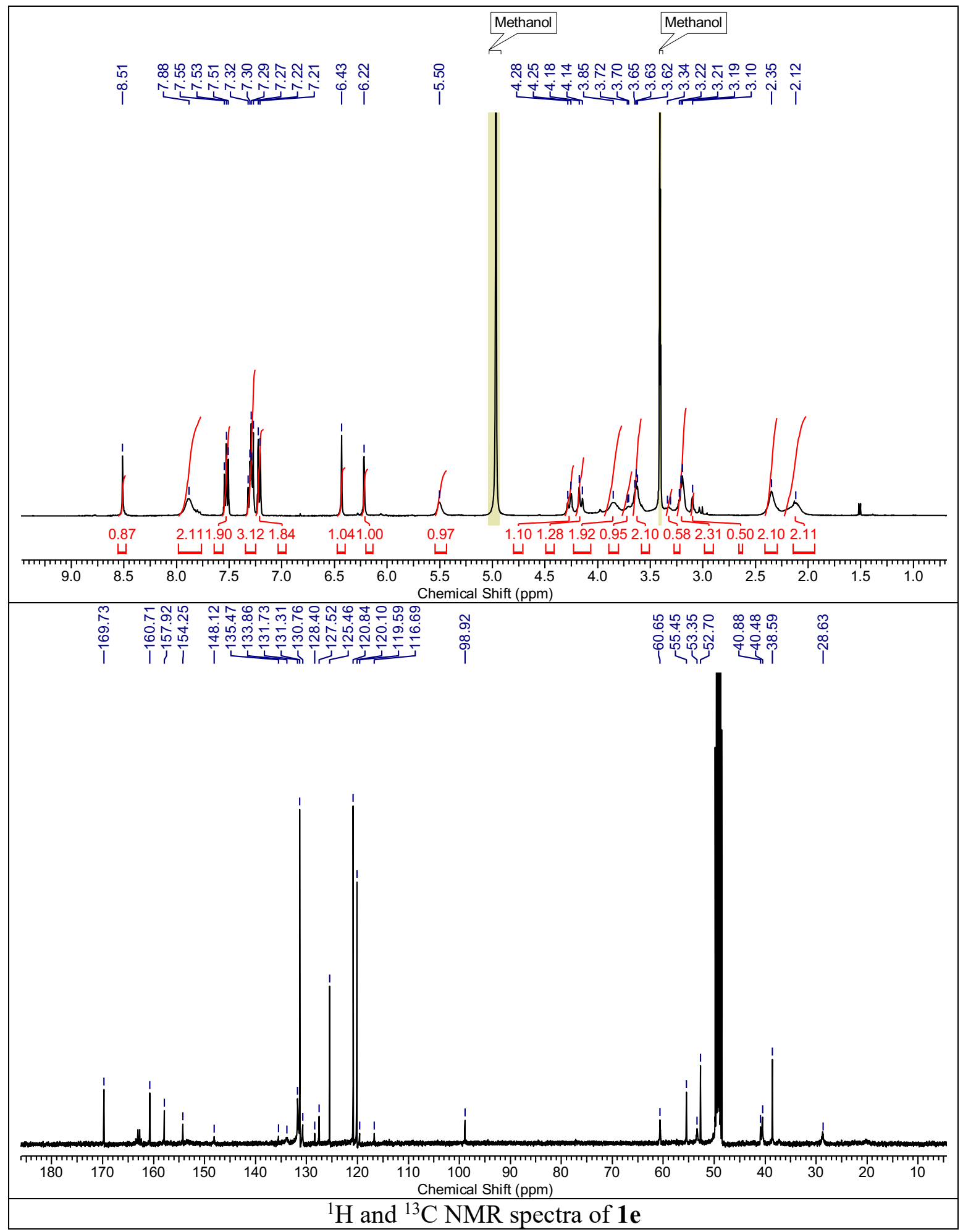




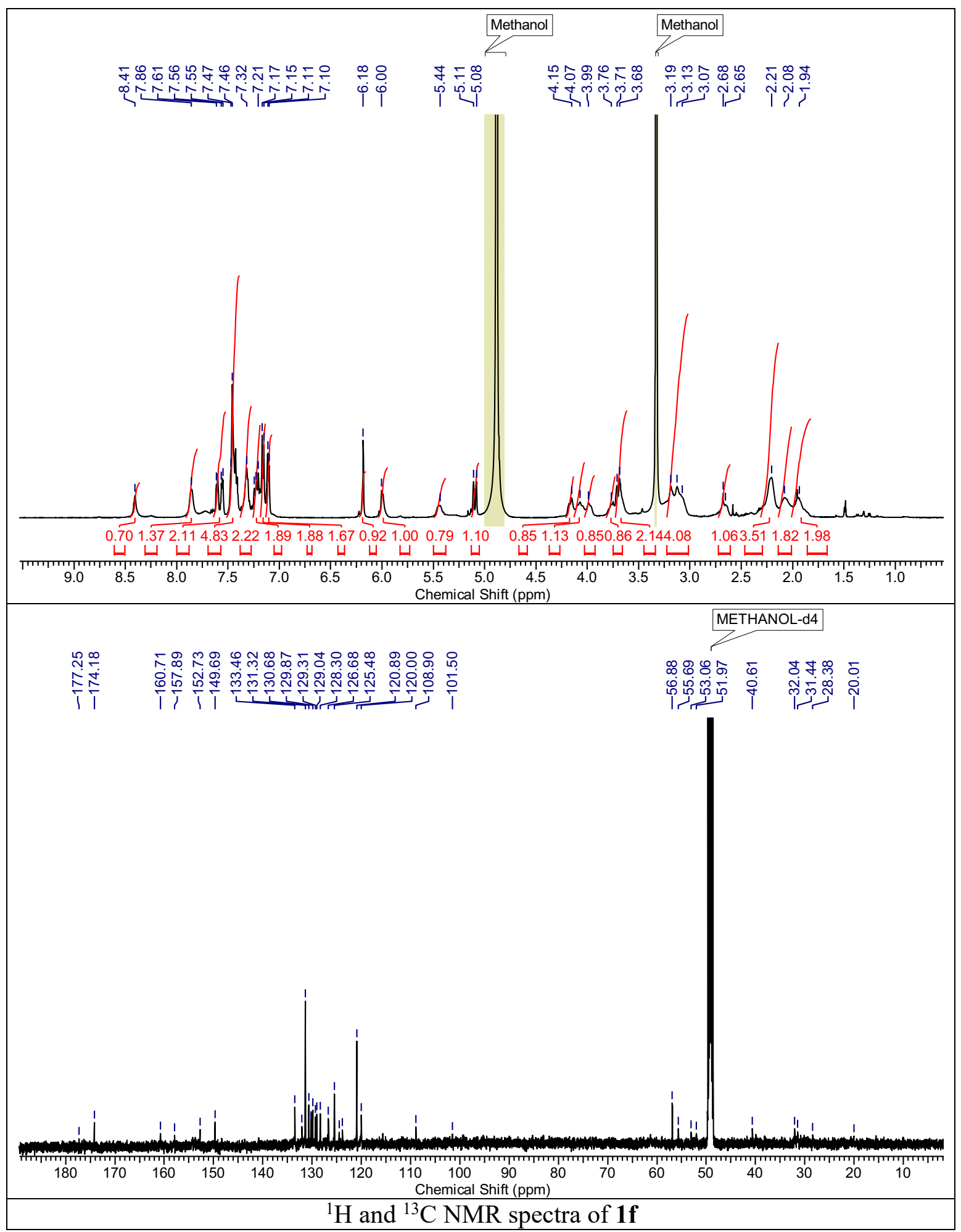




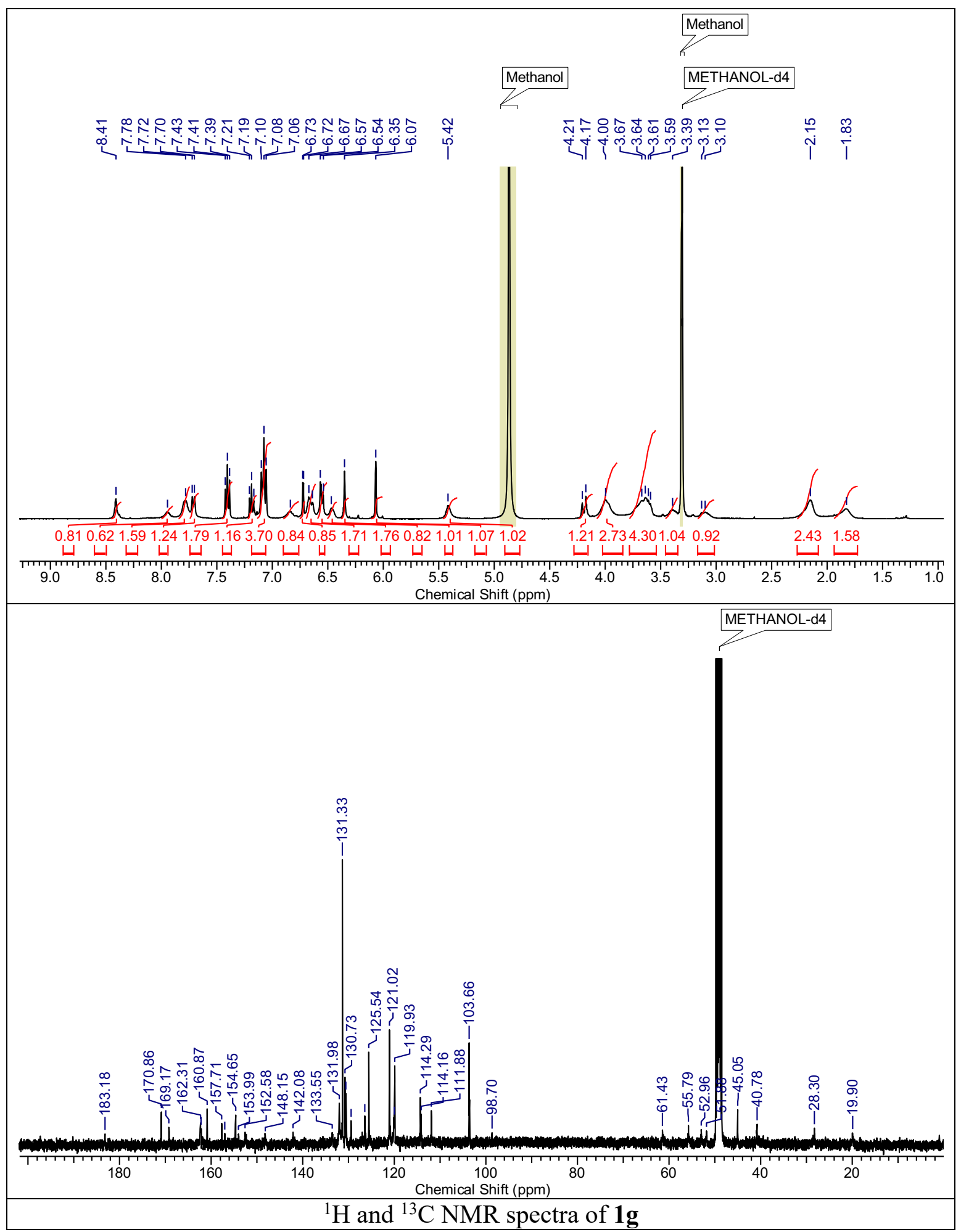




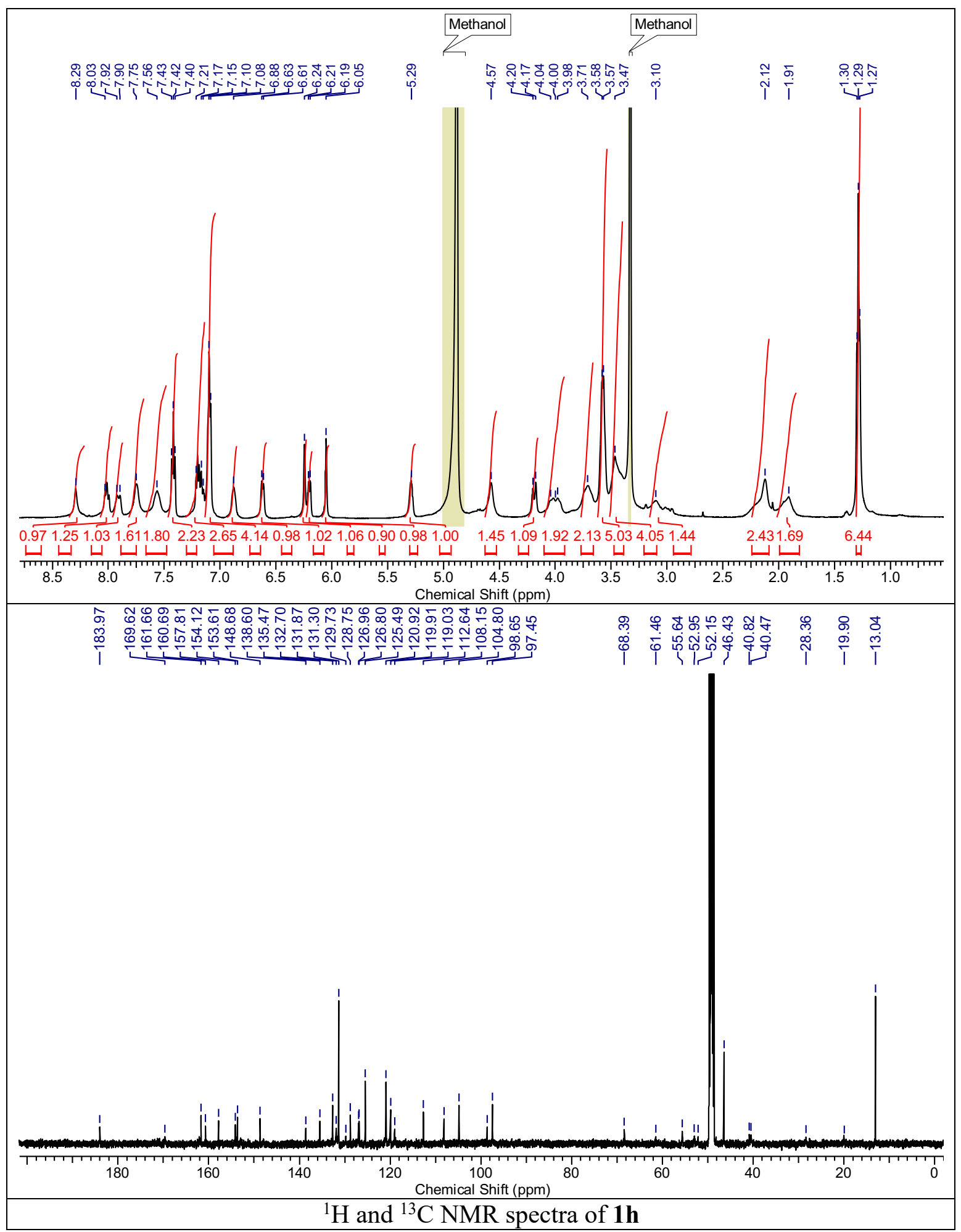




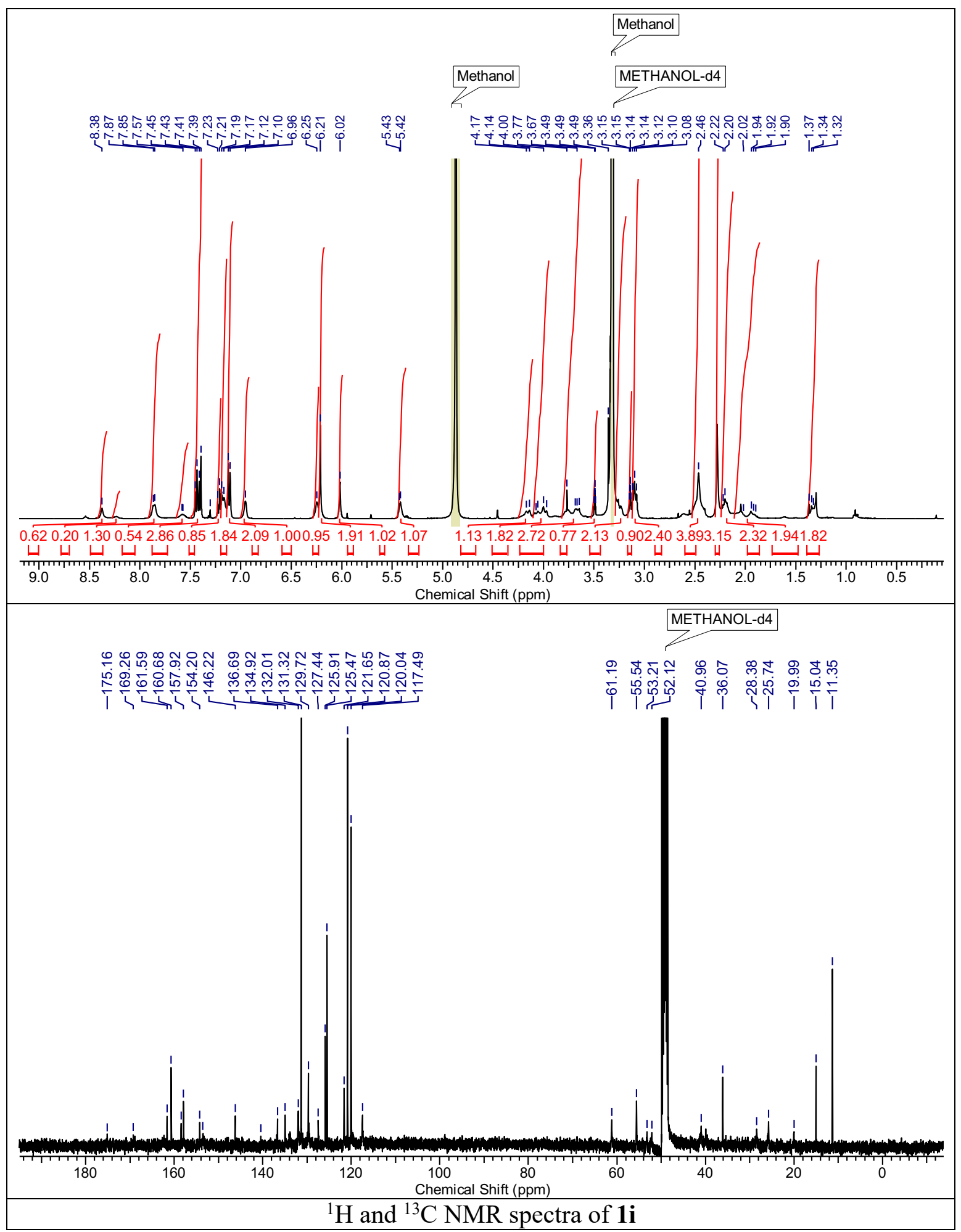




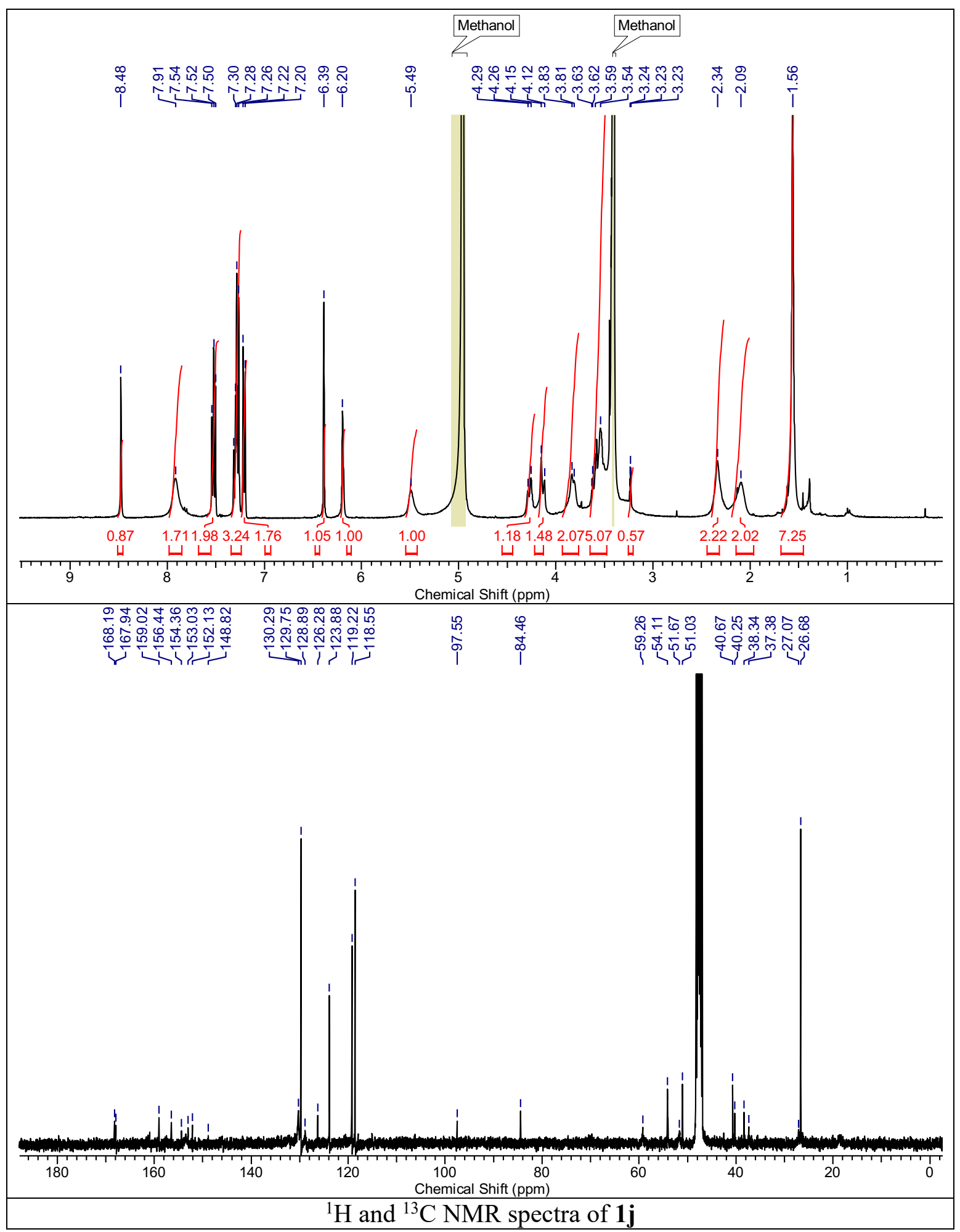




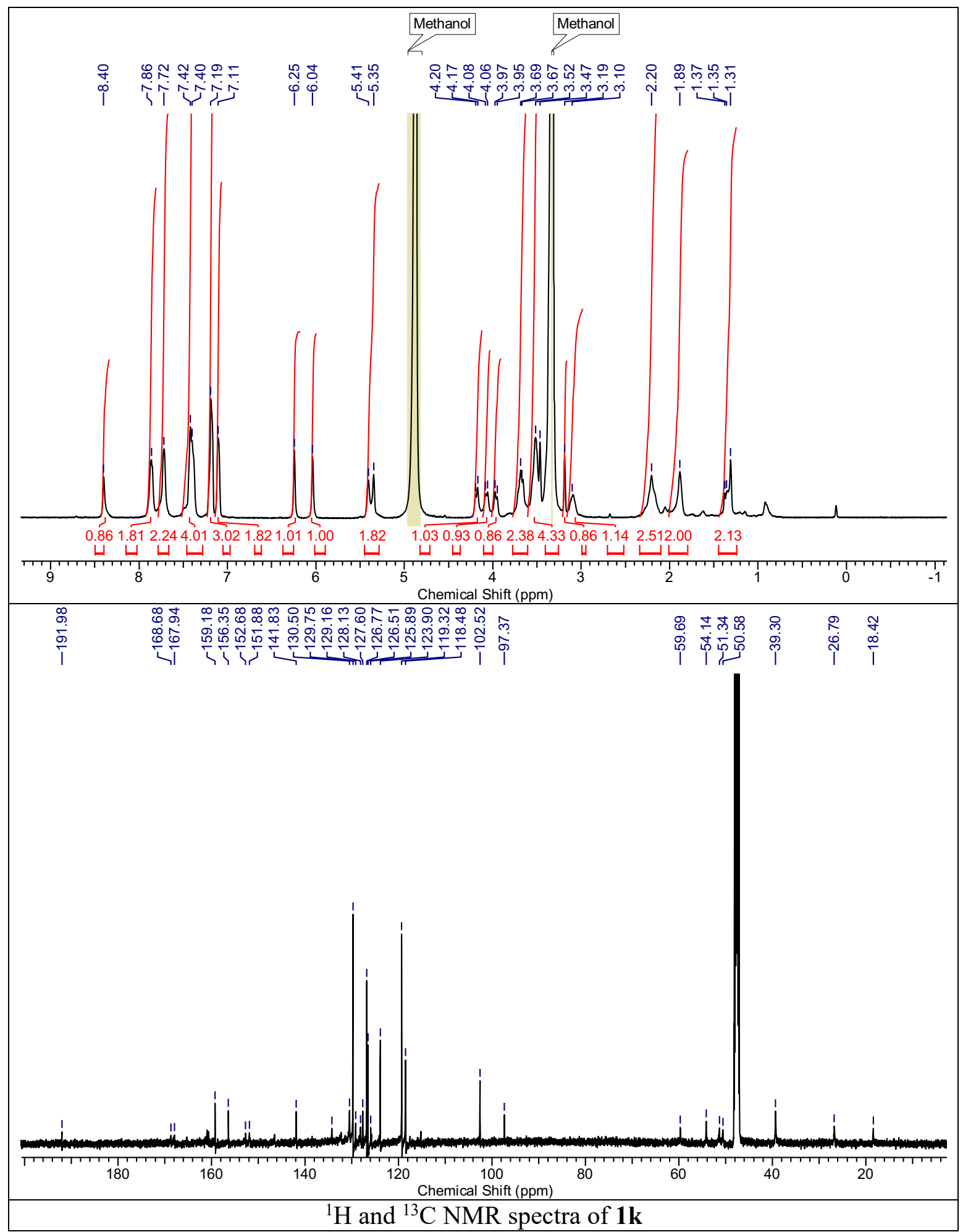




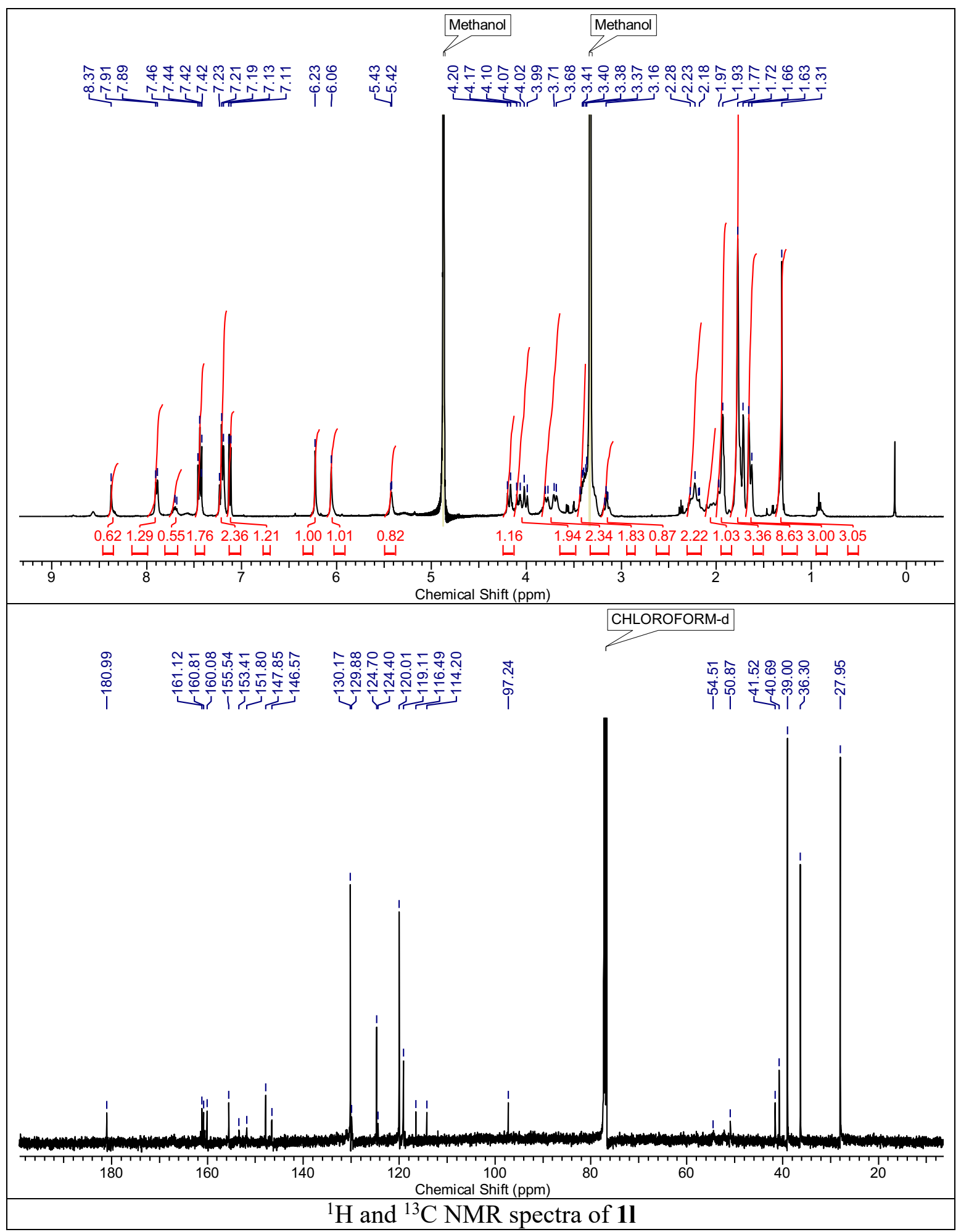




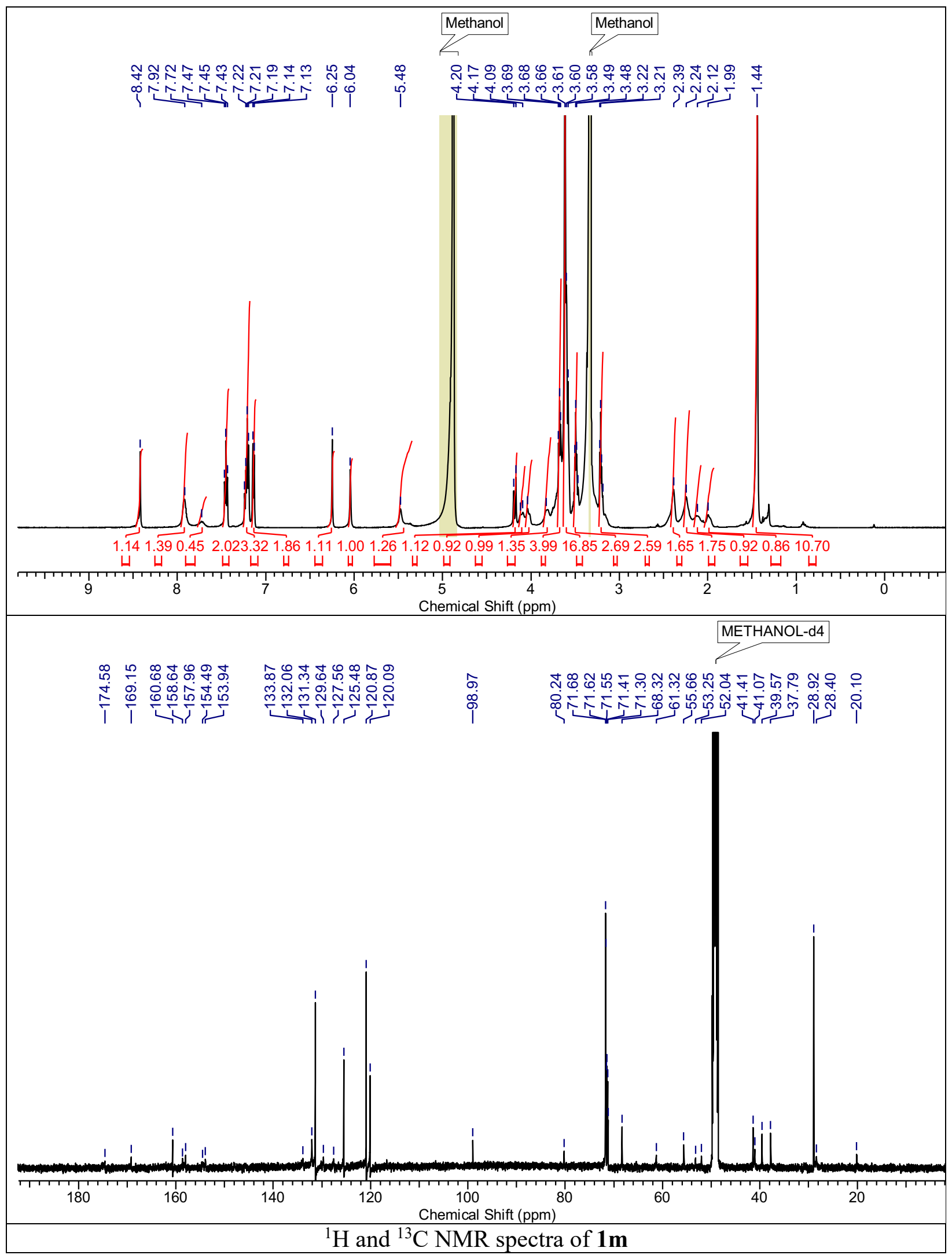




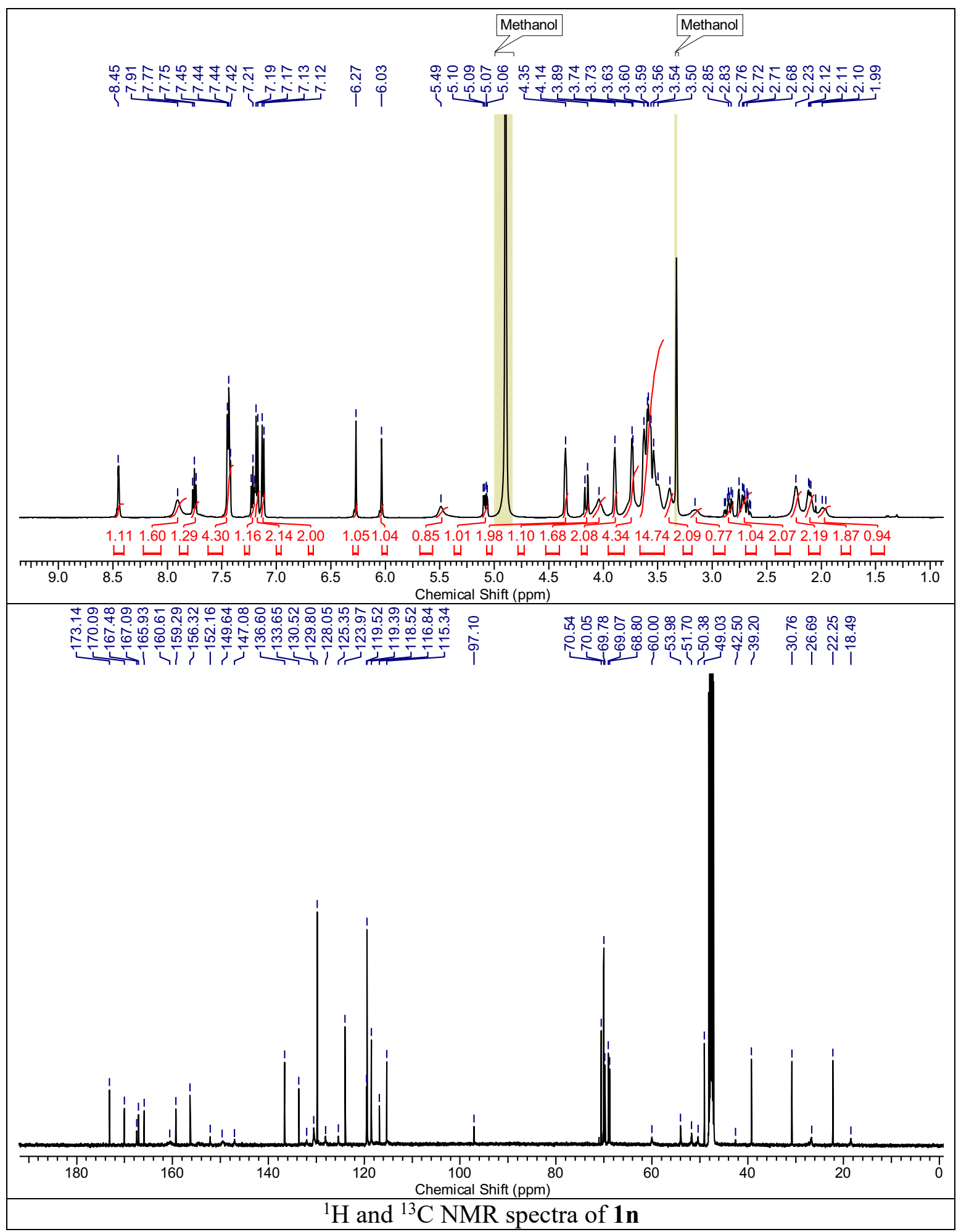




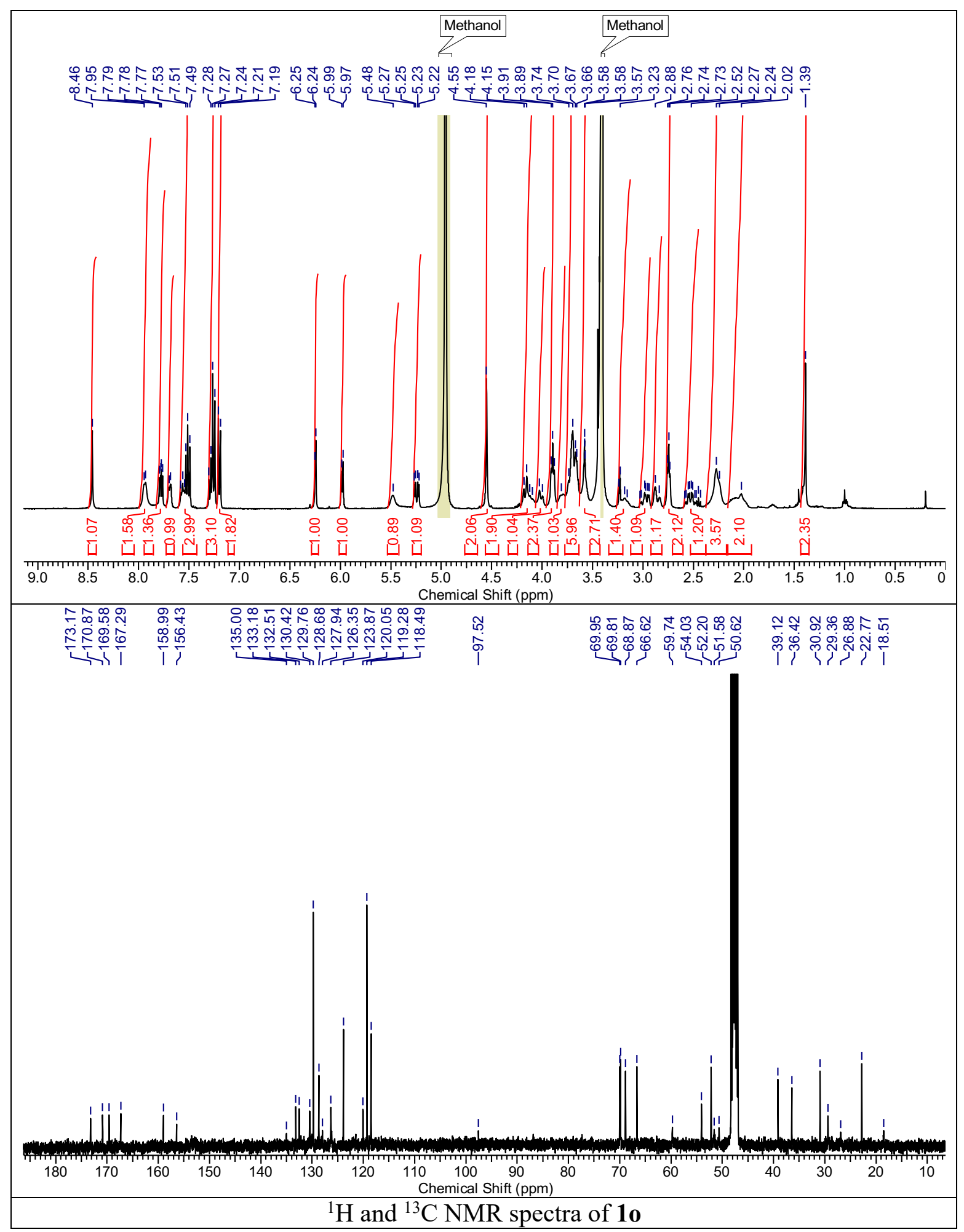




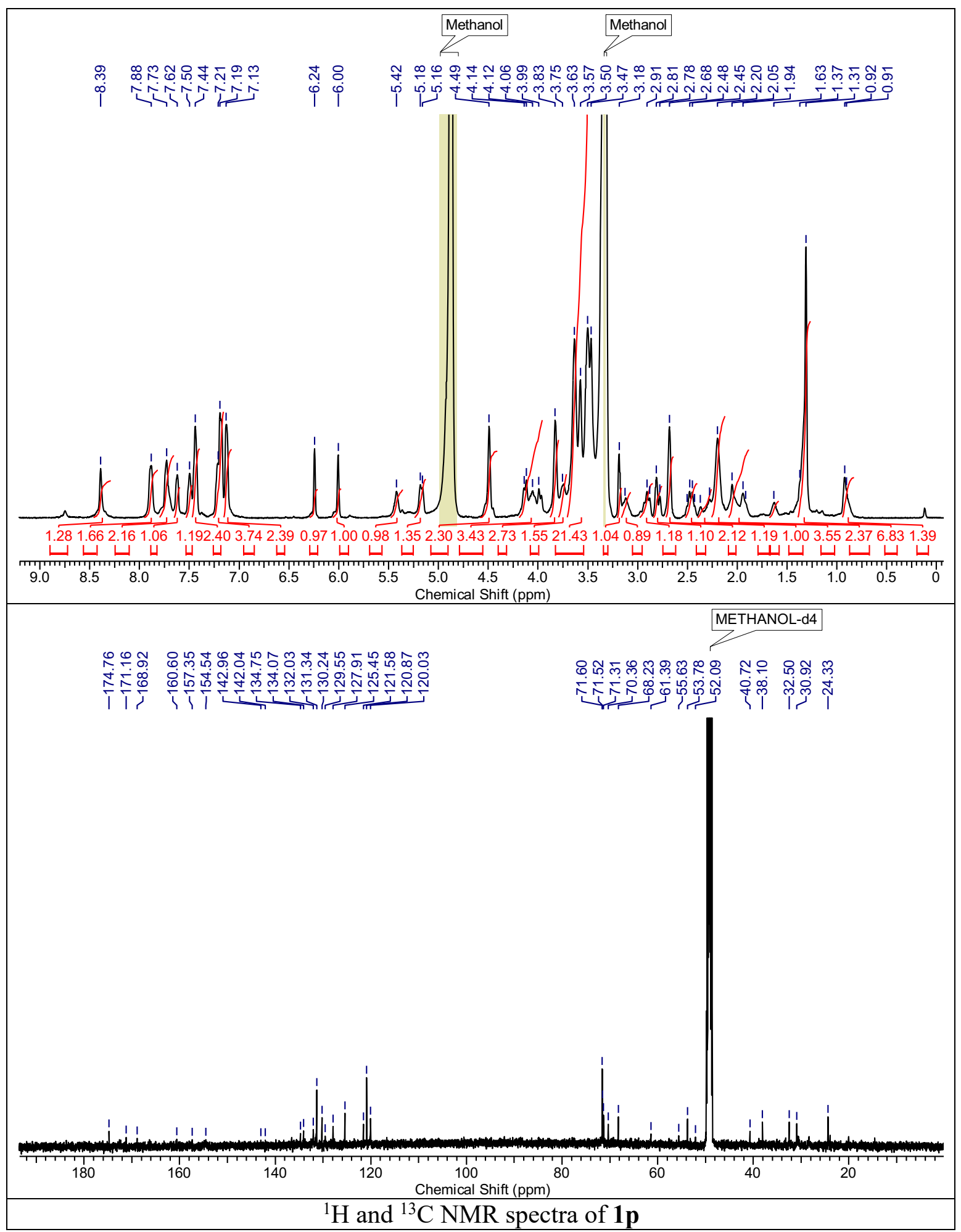




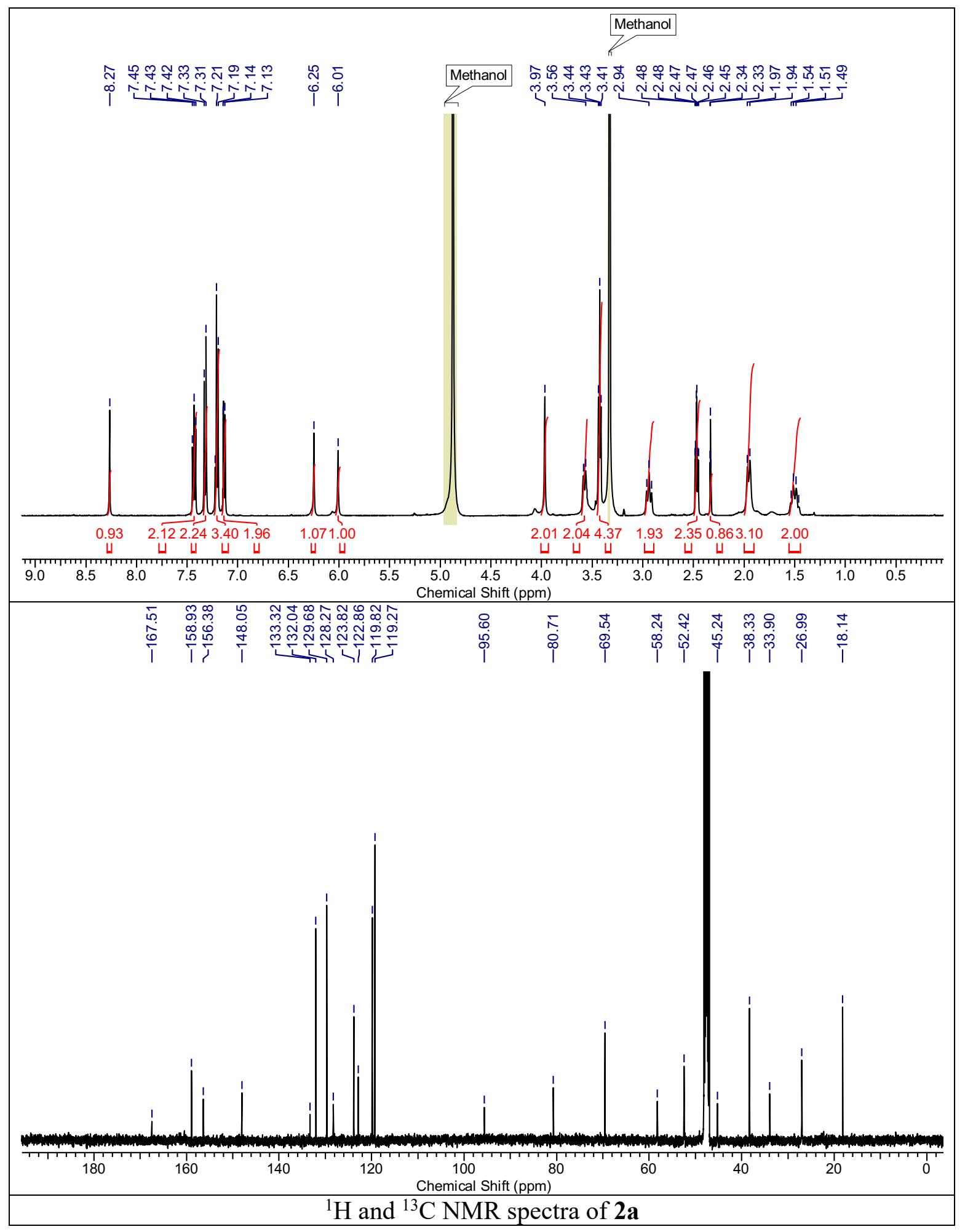




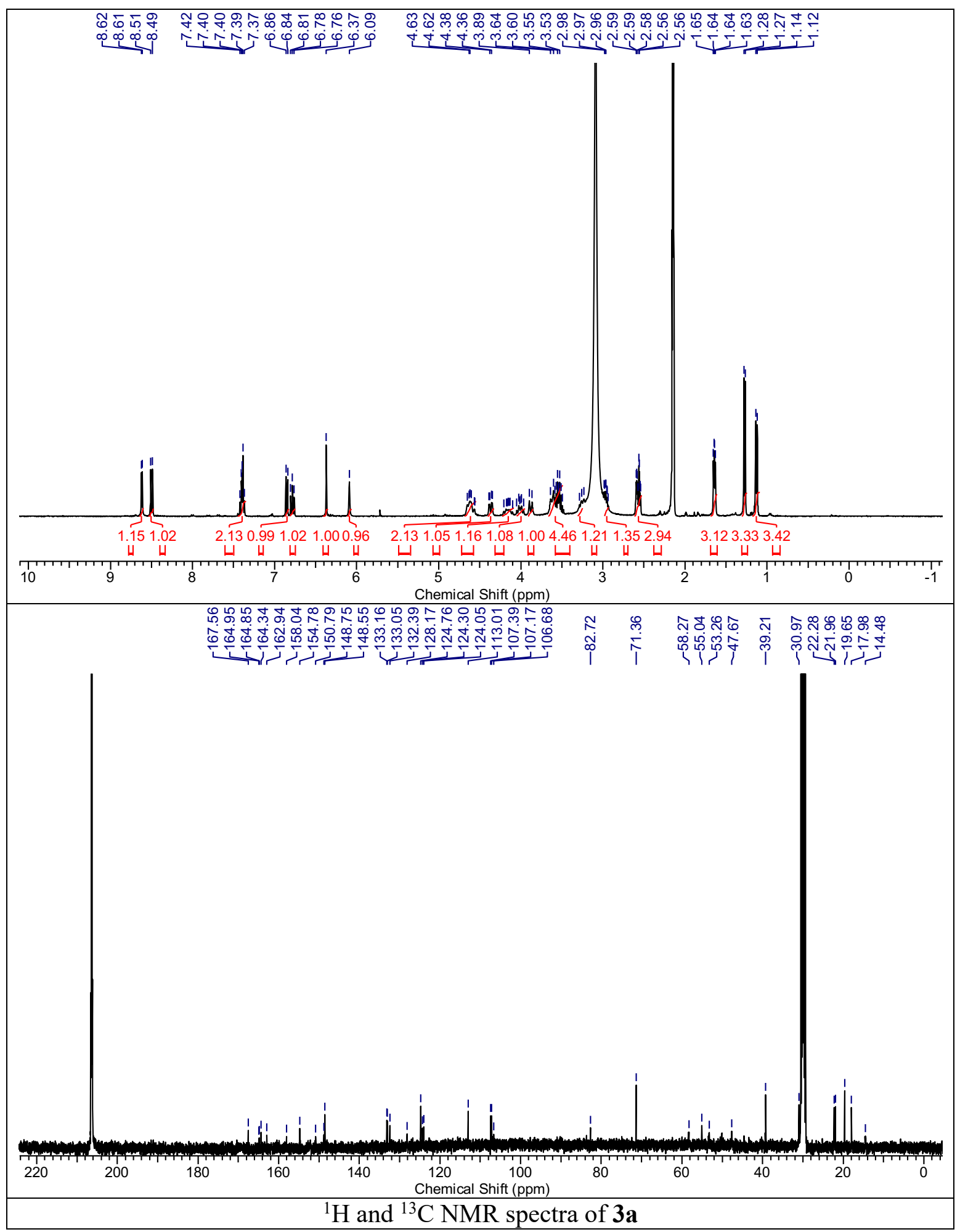




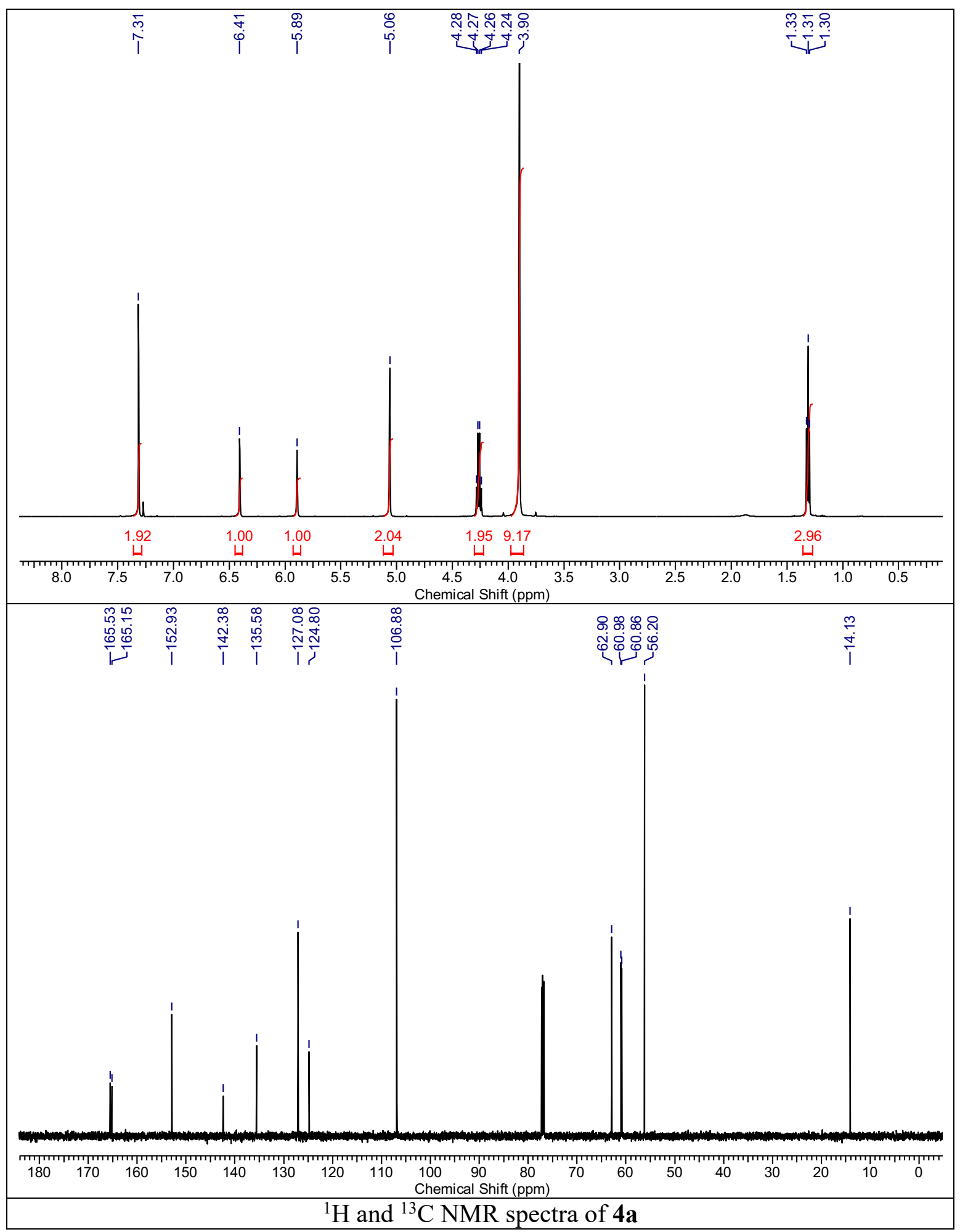

